\title{
Article
}

\section{Perceptual fluency effects in judgments of creativity and beauty: creative objects are perceived fluently yet they are visually complex}

Christensen, Bo T., Ball, Linden and Reber, Rolf

Available at http://clok.uclan.ac.uk/30766/

Christensen, Bo T., Ball, Linden ORCID: 0000-0002-5099-0124 and Reber, Rolf (2020) Perceptual fluency effects in judgments of creativity and beauty: creative objects are perceived fluently yet they are visually complex. Journal of Cognitive Psychology, 32 (1). pp. 45-66. ISSN 2044-5911

It is advisable to refer to the publisher's version if you intend to cite from the work. http://dx.doi.org/10.1080/20445911.2019.1689986

For more information about UCLan's research in this area go to http://www.uclan.ac.uk/researchgroups/ and search for <name of research Group>.

For information about Research generally at UCLan please go to http://www.uclan.ac.uk/research/

All outputs in CLoK are protected by Intellectual Property Rights law, including Copyright law. Copyright, IPR and Moral Rights for the works on this site are retained by the individual authors and/or other copyright owners. Terms and conditions for use of this material are defined in the policies page. 
Running Head: PERCEPTUAL FLUENCY, CREATIVITY AND BEAUTY

\title{
Perceptual Fluency Effects in Judgments of Creativity and Beauty: Creative Objects are Perceived Fluently yet they are Visually Complex
}

\author{
Bo T. Christensen \\ Copenhagen Business School, Copenhagen, Denmark \\ Linden J. Ball \\ University of Central Lancashire, Preston, UK \\ Rolf Reber \\ University of Oslo, Oslo, Norway
}

\author{
Address of Correspondence: \\ Professor Bo T. Christensen \\ Department of Marketing \\ Solbjerg Plads 3 \\ 2000 Frederiksberg C \\ DENMARK \\ Phone: +45 38152123; email: bc.marktg@ @ cbs.dk
}




\begin{abstract}
Perceptual fluency typically has a positive influence on aesthetic evaluations of beauty, but few studies have examined its influence on creativity evaluations. Creativity has two facets, originality and quality. If creativity judgments involve estimating product originality, such judgments may be associated with perceptual disfluency, while product quality may be associated with perceptual fluency. We examined the relationship between perceptual fluency and judgments of creativity and beauty across seven experiments. Creativity judgments were affected by most perceptual fluency sources. We observed a highly-fluent-is-beautiful-andcreative relation when testing repeated exposure and figure-ground contrast. Prototypicality displayed a high-fluency-is-beautiful relation, with creativity judgments unaffected. Visual complexity displayed a consistent disfluent-is-creative effect, with mixed results for beauty. For creativity (but not beauty) evaluations, increased saliency of visual complexity led to discounting fluent-is-creative effects, supporting the hypothesis that there are at least two fluency pathways to creativity judgments that take both originality and quality into account.
\end{abstract}

Keywords: Perceptual fluency, evaluation, judgment, creativity, beauty 


\section{Perceptual Fluency Effects in Judgments of Creativity and Beauty: Creative Objects are Perceived Fluently yet they are Visually Complex}

How the perception of objects eventually leads to the formation of aesthetic judgments may depend crucially on the type of aesthetic judgment made: the perceptual qualities informing beauty judgments need not be the same as the qualities informing creativity judgments. Consider the following thought experiment: First, think of a "beautiful" chair. What probably comes to mind is a symmetrical chair with simple lines and a high level of contrast. It is likely that the chair will be easily evoked, will feel familiar (perhaps you know it well), and will engender a warm feeling. You have just had a fluent experience. Now, think of a "creative" chair. Most likely a markedly different chair with different qualities comes (more slowly) to mind, perhaps a less simple and less familiar chair. Imagining or encountering creativity, whether in consumer products or in artworks, may be taxing on the mind and not easily experienced (i.e., the process might feel disfluent).

In line with this thought experiment, there are claims in the literature that when perceiving aesthetic or designed objects, a central mediating factor is perceptual fluency, that is, the subjective ease with which mental operations are performed. Researchers espousing the importance of perceptual fluency for aesthetic evaluations argue that such judgments are ultimately rooted in the processing dynamics of the underlying perception. This is characterized by low cognitive resource demands that give rise to processing that is "hedonically marked" (Winkielman, Schwarz, Fazendeiro, \& Reber, 2003), thereby directly linking fluency to positive affect (for reviews see Alter \& Oppenheimer, 2009; Reber, Schwarz, \& Winkielman, 2004a).

Evidence for this high-fluency-liking link comes from self-report measures as well as from psychophysiological indicators of positive affect, such as stronger activity in the facial 
zygomaticus region (associated with smiling), but not in the corrugator region (associated with frowning), as demonstrated by electromyography (Topolinski, Erle, \& Reber, 2015; Winkielman \& Cacioppo, 2001). Making aesthetic judgments therefore reflects not only the content of our thoughts but also the metacognitive experience of processing these thoughts (on metacognitive feelings, see Flavell, 1979; Schwarz \& Clore, 2007), potentially turning feelings into information in judgments (Schwarz, 2011). In sum, fluently processed stimuli elicit positive affect, leading to greater aesthetic preference (e.g., judgments of beauty) for such stimuli compared to disfluently processed stimuli (Clore, 1992; Reber, Winkielman, \& Schwarz, 1998; Winkielman, Halberstadt, Fazendeiro, \& Catty, 2006).

Besides beauty, another key type of aesthetic experience that we have described in our opening thought experiment is creativity (Cropley \& Cropley, 2008). Although the relation between highly fluent processing and judgments of beauty has been extensively studied, we know little about how fluency experiences relate to creativity judgments. The present paper aims to rectify this research gap by addressing the question: What is the relation between perceptual fluency and evaluations of creativity? Although high fluency has been shown to influence attributions of familiarity in the context of beauty judgments, central characteristics of creativity include the assessment of object novelty and distinct object features, that is, the absence of familiarity. As suggested by the chair example above, highly fluent perceptual experiences are associated with beauty, while it is possible that the positive assessment of creativity might be triggered by disfluent processing. Based upon various extant theories of fluency effects in judgment (e.g., Alter \& Oppenheimer, 2009; Reber et al., 2004a; Schwarz, 2004), as well as creativity theory, we derived hypotheses that formed a guiding context for the interpretation of data that we obtained from a series of seven experiments. 


\section{Fluency Theories of Aesthetic Preference}

Fluency theories generally assume that multiple stimulus factors feed into the same global, non-specific experience of subjective ease or difficulty of processing (Bornstein, 1989; Jacoby, 1983; Koriat, 1993). This subjective experience of fluency is reportable (Forster, Leder, \& Ansorge, 2013), and is viewed as occurring at the "fringe of consciousness" (Reber, Wurtz, \& Zimmermann, 2004b), encompassing experiences not only related to perceptual fluency, but also to retrieval fluency (Schwarz, 1998) as well as conceptual fluency, which is derived from meaning (Alter \& Oppenheimer, 2009; Topolinski \& Strack, 2009; Whittlesea, 1993).

In relation to perceptual fluency, a range of stimulus sources have been linked to highly fluent experiences, including visual symmetry (Bertamini, Makin, \& Rampone, 2013; Humphrey, 1997), figure-ground contrast (Reber et al., 1998), visual clarity (Oppenheimer \& Frank, 2008), curvature of contours (Bar \& Neta, 2006), exposure duration (Reber et al., 1998) and perceptual priming (Reber et al., 1998). Furthermore, repeated exposure (Zajonc, 1968) and prototype formation (Winkielman et al., 2006), also make a stimulus easier to process, with the feeling of processing ease either being positive in itself or being confused with a favorable evaluation (Bornstein, 1989).

The hypothesis that fluency is hedonically marked (i.e., ease-is-pleasure; hereafter referred to as "Hedonic-Marking Theory") encapsulates the general principle that people prefer easily processed stimuli because the affective response is positively valenced (Reber et al., 2004a; Winkielman et al., 2003). This Hedonic-Marking Theory of aesthetic pleasure may be contrasted with other fluency theories. Whereas the Hedonic-Marking Theory assumes that an automatic process links subjectively experienced high fluency to positive judgments, other theories have claimed that fluency interpretations are generally based on so-called "naïve 
theories" that may reflect a level of reflective and deliberative attribution, rendering such judgments malleable (see Alter \& Oppenheimer, 2009; Schwarz, 2004). According to this latter view, experienced fluency serves as a ubiquitous "metacognitive cue" in reasoning and social judgment (hereafter referred to as "Cue-Attribution Theory"), but the interpretation of experienced fluency may differ. For example, by manipulating instructions (Briñol, Petty, \& Tormala, 2006) or by introducing a cue-learning paradigm (Unkelbach, 2006), it has been shown that it is possible to manipulate the naïve theories that people apply, thereby reversing the interpretation of high fluency. Research by Cho and Schwarz (2006) indicates that when fluency is manipulated by means of "easy-to-read" versus "difficult-to-read" fonts then participants who are low in Need for Cognition find consumer products to be more innovative when the advertising text is disfluent. Cho and Schwarz additionally found that participants liked the disfluent consumer products more when this disfluency was attributed to high innovativeness reversing the usual link between high fluency and preference.

Given the conceptual relation of creativity to originality and novelty, people may base their creativity judgments on the naïve belief that subjective feelings of disfluency serve as an indicator of object novelty. Further, it has been hypothesized that disfluency may ignite arousal and interest (Graf \& Landwehr, 2015; Labroo \& Pocheptsova, 2016) feeding positively into measures of preference. Insofar as creativity judgments relate to increased arousal and interest (e.g., through novelty perception), then this would predict that disfluent perception might lead to positive attributions in creativity judgments. Finally, fluency attributions have been found to be context-sensitive (Schwarz, 2010), and it has been suggested that preference for novelty may depend on whether the context is security-oriented versus growth-oriented (Gillebaart, Förster, \& Rotteveel, 2012). Although the theoretical explanation varies (task-related naïve beliefs; relation 
to interest and arousal; or contextual moderation), several Cue-Attribution Theories converge to predict that although high fluency is beautiful, we may (at least under certain conditions) expect disfluency-is-creative attributions in aesthetic judgments.

\section{Visual Complexity and Aesthetic Preference}

A central debate in fluency research concerns the explanation of the relation between visual complexity and aesthetic preference, where visual complexity is defined as the number and variety of elements present in a visual scene or image (Berlyne, 1958; Marin \& Leder, 2013;

Joye, Steg, Ünal, \& Pals, 2016; Geert \& Wagemans, in press). Hedonic-Marking Theory would hypothesize a linear relationship between complexity and liking, with increasingly complex stimuli giving rise to decreased liking. Although this relationship has sometimes been found (Eysenck, 1942), visual simplicity does not always lead to more positive affect. Indeed, some studies have instead found an inverted U-shaped relation, with intermediate complexity showing higher preference judgments than either low or high complexity (e.g., Berlyne, 1971; Munsinger \& Kessen, 1964; Vitz, 1966). Furthermore, it has been found that people sometimes derive aesthetic pleasure from viewing complex or visually challenging objects or scenes (e.g., Armstrong \& Detweiler-Bedell, 2008; Joye et al., 2016), including complex visual artworks (Keltner \& Haidt, 2003), ambiguous pictures (Jakesch, Leder, \& Forster, 2013) or fractals (Joye et al., 2016). In an analysis of variables that increased aesthetic pleasure, Martindale, Moore, and Borkum (1990) found that more complex stimuli were liked more because they were considered to be more meaningful.

These mixed findings concerning visual complexity and aesthetic preference present a modest challenge to fluency theories, making the effects of visual complexity a contested issue. Indeed, several explanations have been brought forward in attempts to explain the relation 
between visual complexity and fluency (e.g., Reber et al., 2004a; Graf \& Landwehr, 2015; see also Ball, Threadgold, Marsh, \& Christensen, 2018). Reber et al. (2004a), for example, argued that low levels of complexity might make the source of fluency salient, thereby suppressing the normal high-fluency-liking attribution. As complexity increases, the salience of the source of fluency decreases, enhancing aesthetic liking. Further increases in complexity will eventually reduce processing fluency and thus will reduce aesthetic liking. In this way an inverted U-shaped relation between visual complexity and aesthetic preference might arise in the case of complexity manipulations that make the source of experienced fluency particularly salient at the "simpler" end of the complexity continuum.

\section{Creativity and Aesthetic Appreciation}

Assessing creativity is an important part of assessing design qualities in consumer products (Christensen, Kristensen, \& Reber, 2015) and in judging the novelty of an artwork in its temporal and historical context (Bullot \& Reber, 2013). Although perceived creativity and beauty are two central and important forms of aesthetic appreciation, they are nevertheless theoretically and empirically distinct constructs. Past studies distinguishing between subjective measures of creativity and beauty have consistently documented (using factor-analytic approaches) that beauty and creativity load on different factors, whether in the evaluation of art (Hagtvedt, Hagtvedt, \& Patrick, 2008; Kozbelt, 2004), consumer products (Horn \& Salvendy, 2009) or websites (Zeng, Salvendy, \& Zhang, 2009). These studies offer strong support for the view that creativity and beauty are distinct forms of aesthetic evaluation, which might also be affected differentially by perceptual fluency.

The creativity literature consensually defines creativity in terms of the qualities of the products resulting from the creative process (e.g., Mayer, 1999; Stein, 1953; Runco \& Jaeger, 
2012), which include their originality (or novelty) and their usefulness (or domain value). The perception of originality has been claimed to be the most important characteristic of creativity (e.g., Diedrich, Benedek, Jauk, \& Neubauer, 2015; Runco \& Charles, 1993; Zhou, Wang, Song, $\& \mathrm{Wu}, 2017)$. Evaluating creativity (i.e., originality and usefulness) in relation to perceived objects may be challenging as necessary information may not be currently available, such as historical traces of the object relative to its category or direct comparisons to the qualities of other objects. This information has instead to be drawn from one's memory of encountered exemplars. Nevertheless, when tasked with trying to perceive creativity, the individual still needs to try to assess originality and usefulness. This is a common situation in novice art appreciation and consumer behaviour: the individual would like to assess the creative value of the object (artwork or consumer product) but they lack relevant information and background domain knowledge. How do people assess creativity when placed in such a perceptual situation? One possibility is that they might try to base their assessment on the subjectively felt ease or difficulty of perceiving the object, that is, they might base their assessment on perceptual fluency and the accompanying subjective feelings of familiarity or novelty.

The received definition of creativity specifies that creativity is attributed to outcomes or products, with the perception of creativity pertaining to the identification of the relative advantage of a product against other products in the same domain or category in terms of its originality (i.e., being historically first) and its usefulness (i.e., being more useful). The task of perceiving and judging creativity is thus a different matter from perceiving beauty. Beauty is centrally a judgment of how the object is experienced in the eye of the beholder, which makes subjective feelings a relevant source of information to consider (Schwarz, 2011). Theoretically, creativity judgments pertain to the perception of attributes of objects, making subjective 
experiences much less important: the perceiver should try to establish whether the object is indeed the first of its kind and whether it genuinely has relative advantages in terms of usefulness compared to other objects in the same category. Creativity perception is, therefore, not an act of assessing individual subjective experiences, but is rather an act of trying to assess objectively the qualities of objects while trying to discount situationally fluctuating or individual, idiosyncratic perceptual factors that may otherwise affect the assessment. In this way the perceiver of creativity (but not the perceiver of beauty) should look out for indicators as to whether their assessment is attributable to contextual or individual factors relating solely to personal experiences in order to discount them from the assessment.

The perception of object uniqueness and its relative value highlight the importance of detecting features that make the object stand out qualitatively from other objects in the domain. That is, the object should have distinctly unique and easily detectable features. The object should, at the feature level, be qualitatively different in valuable ways from other exemplars. One important indicator of stimulus distinctiveness is visual complexity. There is some scant evidence in the literature that the evaluation of creativity diverges from the evaluation of beauty when it comes to visual complexity. Complexity has been linked to creativity judgments in products (O'Quin \& Besemer, 1989), with higher complexity ratings being associated with higher creativity ratings. Furthermore, in their factor-analytic study, O'Quin and Besemer (1989) found that complexity loaded on the same factor as other originality measures (i.e., original, surprising and germinal), but not on the same factors as the usefulness measures. In addition, Young and Racey (2009) found a linear, positive relation between stimulus variability and judged creativity across four experiments. However, Ball et al. (2018) did not find that the complexity of abstract artwork influenced creativity ratings. Research has also found evidence 
that creative individuals prefer complex stimuli (Eisenman \& Rappaport, 1967; Ziv \& Keydar, 2009). Past research thus indicates that visual complexity may be one important source of perceptual fluency, where creativity and beauty attributions might diverge.

\section{The Present Experiments and Predictions}

The present set of seven experiments explored how perceptual fluency affects aesthetic judgments of creativity and beauty for presented stimuli. Across our experiments we tested four different perceptual sources of fluency (visual complexity, repeated exposure, prototypicality, and contrast) and three different instantiations of visual complexity. Throughout the experiments, beauty judgments serve as a relevant and well-known aesthetic comparison to the novel observations relating to how perceptual fluency influences creativity assessments. Our overarching prediction for beauty judgments based on our review of the literature was that they would, in the main, display a standard high-fluency-liking relation, albeit possibly with an inverted U-shaped relation emerging in the case of visual complexity.

For creativity judgments, three contradictory predictions are suggested that derive from distinct theoretical accounts, albeit with the recognition that these predictions are tentative given the lack of prior research and theorizing on the relation between fluency and creativity. First, the Hedonic-Marking Theory (e.g., Reber et al., 2004a; Winkielman et al., 2003) might posit that the broad hedonic marking of ease-of-perception will influence creative evaluations in a similar, positive manner to beauty judgments. Assuming that creativity carries positive connotations, hedonically marked ease-of-perception might lead to the surprising prediction that creativity assessment is positively influenced by higher feelings of subjective familiarity (lower subjective feelings of novelty). Thus, the prediction would be for creativity judgments to align with beauty judgments in tracking fluency. A similar prediction would hold if people interpret fluency as a 
signal for the usefulness aspect of creativity such that high perceptual fluency might indicate usefulness and therefore lead to higher judgments of creativity. However, given that previous research has shown that beauty and creativity explain different parts of the variance of willingness-to-pay judgments (Christensen et al., 2015), it seems unlikely that creativity judgments will be correlated with beauty judgments and therefore positively related to perceptual fluency.

Second, in Cue-Attribution Theories (e.g., Alter \& Oppenheimer, 2009; Schwarz, 2004), fluency serves as a ubiquitous metacognitive cue that triggers interpretations based on naïve beliefs. Given the close relation between creativity and perceived novelty, it seems plausible that for a product to be judged as creative it would need to be surprising, hard to integrate into present cognitive schemas, at odds with current representations and classification systems, lacking prototypicality and eliciting feelings of unfamiliarity - that is, the product would be closely aligned with perceptual factors that are known to be related to disfluency. Subjective feelings of disfluency might be interpreted as deriving from stimulus novelty, which in the context of a creativity assessment instruction would activate a naïve belief that "subjectively experienced novelty stems from creative sources". Alternatively, evaluating creativity might be closely related to object interest and arousal. Either explanation can be hypothesized to lead to a change in the attribution to fluency cues, that is, higher subjective fluency would be interpreted as stemming from a low degree of source creativity. This attribution should be the same regardless of the type of fluency manipulation that leads to the experience of high fluency (e.g., whether it derives from contrast, complexity, prototypicality or repeated exposure). Although the theoretical explanation varies, several Cue-Attribution Theories converge in predicting that although high-fluency-is-beautiful, we may (at least under certain conditions) expect disfluency- 
is-creative attributions in aesthetic judgments. In this case, respondents would take the originality facet of creativity into account when making creativity judgments.

Third, in alignment with general theories of creativity (what we hereafter refer to as Creativity Theory), the perception of creativity might entail an assessment of the qualities of objects by looking especially for traces of their historical novelty in a class of objects (originality) and object comparisons in terms of advantageous and valuable features (usefulness). If the perceiver is making the creativity assessment without much prior domain expertise and in situations where this object quality information cannot be acquired through further exploration, then the perceiver might instead rely on perceptual indicators that are correlated with perceptual fluency. However, it is possible that originality and usefulness are differentially linked to different sources of fluency, meaning that different manipulations of fluency might result in differential outcomes in terms of creativity judgments. High fluency due to simplicity, prototypicality, repeated exposure and high figure-ground contrast might be taken as a sign of both a lack of originality and a high degree of usefulness. However, instead of high fluency signaling either a lack of originality or a high degree of usefulness for all manipulations, high fluency stemming from one source, for example, simplicity might signal a lack of originality, but high fluency stemming from another source, such as repetition, might signal a high degree of usefulness or quality.

In a situation where the latter, mixed-effects account of creativity judgments holds true, it would be difficult to predict which sources of high fluency might lead to high or low judgments of creativity, respectively. However, such a pattern of results would clearly contradict a central tenet of fluency theory as it is currently formulated, namely, that fluency is a global feeling that does not depend on the fluency source (Reber et al., 2004b). Recently, Silva, Garcia-Marques, 
and Mello (2016) provided evidence that fluency effects may be moderated by the source of fluency. Indeed, if our experiments showed that different sources of fluency lead to different outcomes on creativity judgments, it would support the view that people draw different inferences from high fluency when it derives from different sources. The Creativity Theory explanation is similar to the Cue-Attribution account in pointing to inferences drawn from a fluency cue, but with the key difference being that distinct sources of fluency may affect the perception of the two main qualities of creativity (originality and usefulness) in different ways. A fluency experience would thus not serve as one global cue, but would rather modulate creativity perception through several distinct cues dependent on the fluency source, which would relate locally and perhaps in opposing ways to the perception of originality and usefulness.

\section{Analysis Strategy}

Our analysis strategy for testing hypothesized relationships involved examining the interaction between judgment type (creativity vs. beauty) and the fluency factor that was manipulated in each experiment. This interaction was assessed via a repeated-measures analysis of variance (ANOVA) in which judgment type (creativity vs. beauty) was treated as a univariate factor. We do not report main effects for judgment type or for each fluency manipulation as we believe that these effects are either of limited conceptual value or, in the case of the fluency manipulations, are conceptually meaningless as they involve a combination of beauty and creativity ratings. Furthermore, in the experiments where we manipulated multiple fluency factors we do not report all possible interaction effects as we did not have a priori hypotheses in mind to inform these analyses.

In all experiments, creativity and beauty ratings occupied a similar range on the response scales such that we opted to undertake all repeated-measures ANOVAs based on the raw 
response values. When reporting our results, we initially present the predicted interaction between the judgment condition (creativity vs. beauty) and each fluency manipulation. This is then followed by the reporting of planned linear contrasts for the fluency manipulation in each judgment condition (creativity and beauty) based on our stated hypotheses. For the fluency manipulation of visual complexity, the planned contrasts additionally include tests for quadratic effects for beauty judgments, given that prior research has sometimes found such quadratic (i.e., inverted U-shaped) effects, as discussed in our prior literature review ${ }^{1}$.

\section{Experiment 1}

Our first experiment aimed to test for the existence of a possible differential fluency effect arising from visual complexity for judgments of beauty and creativity. To this end we used aesthetic stimulus materials in the form of paintings by Pablo Picasso.

\section{Method}

The experiment involved 63 volunteer participants who were asked to judge Picasso paintings for beauty and creativity ${ }^{2}$. Forty-two participants were from University of Bergen (27

\footnotetext{
${ }^{1}$ We did not predict quadratic effects for how visual complexity would affect creativity judgments, but we do, for the sake of complete reporting, include a footnote in the few instances where significant quadratic effects were found in this respect. For all other fluency manipulations besides visual complexity we did not expect (and we also did not find) significant quadratic effects on either judgments of creativity or judgments of beauty.

${ }^{2}$ Two participants were dropped from the analysis due to missing data as repeated-measures ANOVA is ill equipped to handle such missing data. For the same reason a few participants were also omitted from the analyses for other experiments: Experiment 2 (1 participant), Experiment 3
} 
female; mean age 21 years) and 21 were from Copenhagen Business School (11 female; mean age 49 years).

In a prior norming study, 20 participants who did not take part in the main study viewed 129 Picasso paintings and judged them for complexity using a $10 \mathrm{~cm}$ Visual Analogue Scale (VAS) that appeared on-screen and ranged from 0 (labelled as "simple") to 100 (labelled as "complex"). These 129 paintings were selected to represent a mixture of styles and excluded the most well-known Picasso paintings. Participants' ratings enabled the creation of five evenlyspaced categories of stimulus complexity with 6 pictures at each complexity level, for a total of 30 Picasso paintings used in the main study. The mean complexity ratings in ascending order across the five complexity levels were: $28.8,40.4,50.4,59.7$ and 71.7 . There was roughly a $10-$ point gap between each complexity level, with paintings being selected for each level to ensure a mixture of styles. The standard deviations for each level were low and broadly similar.

In the main experiment each participant rated the same series of 30 paintings twice using a VAS, once for beauty and once for creativity, for a total of 60 judgments (see Figure 1 for sample stimuli). Experiment 1 was thus a 2 (judgment condition: creativity vs. beauty) x 5 (visual complexity) design, with six items in each complexity category. Twenty-nine participants made beauty judgments first ("How beautiful is the picture?"), with the VAS ranging from 0 ("ugly") to 100 ("beautiful"), followed by creativity judgments ("How creative is the picture?"), with the VAS ranging from 0 ("uncreative") to 100 ("creative"). The judgment ordering was reversed for another 34 participants and the stimulus presentation order was independently

(2 participants) and Experiment 5 ( 2 participants). No participants were removed from the analyses for the remaining experiments. 
randomized for each participant for both the beauty judgments and the creativity judgments. The paintings were presented for $2 \mathrm{~s}$ each on a 17 inch $(43.18 \mathrm{~cm})$ computer monitor using E-prime ${ }^{\circledR}$ presentation software (Psychology Software Tools Inc., www.pstnet.com), with each picture being preceded by a fixation cross that was presented for $500 \mathrm{~ms}$.

***Please insert Figure 1 about here***

\section{Results and Discussion}

None of the experiments that we report here gave rise to any order effects for either creativity or beauty judgments, all $F_{\mathrm{s}}<2.79$. The judgments from both orders were therefore combined for subsequent analyses in all experiments.

Descriptive data for Experiment 1 are presented graphically in Figure 2, whereas Table 1 provides an overview of the main effects of the fluency manipulation across all seven experiments reported in this paper. Repeated-measures ANOVA revealed that the predicted interaction between complexity and judgment condition (creativity vs. beauty) was significant, $F(4,248)=73.84, p<.001, \eta p^{2}=0.55$. The planned contrast for the linear trend for creativity judgments ${ }^{3}$ was highly significant and increasing, $F(1,62)=158.50, p<.001, \eta_{p}^{2}=0.72$, whereas the planned contrast for the linear trend for beauty judgments was not significant, $F(1$, 62) $=0.47, p=.49, \eta_{p}{ }^{2}=0.01$, instead displaying a significant quadratic effect (i.e., an inverted U-shaped relation), $F(1,62)=20.47, p<.001, \eta_{p}{ }^{2}=0.25$.

***Please insert Figure 2 about here***

\footnotetext{
${ }^{3} \mathrm{We}$ did, in addition, find a non-planned quadratic effect (U-shaped) for creativity judgments, $F(1,62)=13.56, p<.001, \eta_{p}^{2}=0.18$, albeit with a substantially reduced effect size compared to the linear effect.
} 
****Please insert Table 1 about here***

The results of Experiment 1 reveal a differential effect of visual complexity on judgments of creativity and beauty. Whereas complexity showed a linear increasing relationship for creativity judgments there was instead an inverted U-shaped relationship for beauty judgments, similar to earlier observations (e.g., Berlyne, 1971; Munsinger \& Kessen, 1964; Vitz, 1966). As Figure 2 demonstrates, it was the more complex categories of stimuli that primarily displayed this differential effect across creativity and beauty judgments.

The positive linear relationship between complexity and creativity runs counter to the expectations derived from the Hedonic-Marking Theory that creativity judgments should track fluency. By contrast, the data map onto what would be expected through Cue-Attribution Theories, whereby naïve beliefs about the association between complexity and creativity could drive judgments. The data do not contradict expectations derived from Creativity Theory, proposing that objective distinctiveness may serve as an indicator of product uniqueness due to originality and usefulness. In light of the present results, complexity would indicate originality.

We acknowledge that it cannot be completely ruled out that the present experiment might have confounded complexity and artistic style. Although a mixture of painting styles was sought for each complexity category it was not possible to have exactly the same styles represented equally across all categories. This was because some styles were simply judged to be somewhat complex (as in Picasso's cubist paintings), whereas others were judged to be somewhat simple (as in some of Picasso's drawings). A confound of style and complexity could potentially also have led to different levels of emotionality at different levels of complexity if certain levels of visually complexity were more emotionally evocative. Despite these possible confounds, it is noteworthy that the observed effects of complexity on judgments of creativity and beauty were 
different, large and significant in the domain of art appreciation. To account for the limitations of Experiment 1 we aimed to replicate the effects with more controlled stimuli in Experiments 2 and 3 .

\section{Experiment 2}

Experiment 2 aimed to replicate the differential fluency effects of visual complexity on judged beauty and creativity with highly controlled experimental stimuli as opposed to the naturalistic stimuli used in Experiment 1. Based on indications from past research, figural variety was identified as a likely instantiation of complexity that might be expected to impact differentially on beauty and creativity judgments.

\section{Method}

Forty-five undergraduates from the University of Bergen (27 female; mean age 23 years) were asked to judge 16 images that varied across the visual complexity dimension of figural variety. The presented images each involved a $5 \times 5$ grid, with one figure presented in each grid cell. The number of different figures used in each grid provided a straightforward and controlled way to manipulate complexity. The simplest images had the same figure in all 25 grid cells, whereas the most complex images had unique figures in each grid cell. The images had 8 levels of complexity and 2 images were presented at each level, with different colour schemes. Experiment 2 was thus a 2 (judgment condition: creativity vs. beauty) x 8 (visual complexity) design, with two items in each complexity category.

In a pilot study, 21 participants who did not participate in the main study judged all 16 images for complexity on a VAS that ranged from 0 ("simple") to 100 ("complex") to check that the manipulation provided approximately evenly-spaced levels of judged complexity. This was found to be the case, with the mean complexity ratings from lowest to highest complexity as 
follows: $12.3,18.9,25.6,37.2,47.1,53.4,62.5$ and 74.4 . In other respects, the set-up was identical to Experiment 1 in terms of randomization and the counterbalancing of orders for creativity and beauty judgments. The presentation duration for stimuli was again $2 \mathrm{~s}$.

In the main experiment, 22 participants first made beauty judgments ("How beautiful is the picture?") on a VAS ranging from 0 ("ugly") to 100 ("beautiful") followed by creativity judgments ("How creative is the picture?") on a VAS ranging from 0 ("uncreative") to 100 ("creative"), with judgment ordering reversed for the other 23 participants. To test whether fluency was related to perceptions of familiarity and originality, an additional 8 participants who did not participate in the main experiment judged the images for familiarity (from "familiar" to "unfamiliar"), and a further 10 participants judged the images for originality (from "original" to "unoriginal").

\section{Results and Discussion}

A repeated-measures ANOVA on the judgment data revealed that the predicted interaction between visual complexity and judgment condition (creativity vs. beauty) was significant, $F(7,308)=32.81, p<.001, \eta_{p}{ }^{2}=0.43$ (see Figure 2). The planned contrast for the linear trend for creativity judgments was highly significant and increasing, $F(1,44)=51.14, p<$ $.001, \eta_{p}{ }^{2}=0.54$, whereas the planned contrast for the linear trend for beauty judgments, whilst also significant, was decreasing, $F(1,44)=11.09, p=.002, \eta_{p}{ }^{2}=0.20$, with no significant quadratic trend, $F(1,44)=1.42, p=.24, \eta_{p}^{2}=0.03$ (see Table 1 ). The analyses revealed that the linear trend for familiarity judgments was increasing, $F(1,7)=13.03, p=.01, \eta_{p}{ }^{2}=0.65$, whereas the linear trend for originality judgments was decreasing, $F(1,9)=18.48, p=.002, \eta_{p}^{2}$ $=0.67$ (i.e., complex images are unfamiliar and original; simple images are familiar and unoriginal). 
These results replicate key findings from Experiment 1, supporting the existence of a clear differential effect of complexity on judgments of creativity and beauty across eight complexity categories (i.e., complex images are creative yet ugly, whereas simple images are uncreative yet beautiful; see Table 1).

In interpreting the beauty data for Experiment 2, we note the fragility of the inverted Ushaped relationship between stimulus complexity and beauty that was seen in Experiment 1 . For the creativity data, however, the evidence that increasingly complex images are viewed as increasingly creative may be interpreted in the same way as equivalent findings in Experiment 1.

\section{Experiment 3}

In Experiment 3 we wished to examine simultaneously two different instantiations of complexity in order to explore the generality of the disfluent-is-creative effect observed in Experiments 1 and 2. To this end, Experiment 3 manipulated two distinct instantiations of visual complexity, that is, figural variety and number of elements.

\section{Method}

Seventy-three undergraduates from the Copenhagen Business School (31 female; mean age 22 years) were asked to judge simple images. The same kinds of grids were used as stimuli as were employed in Experiment 2, with figures in each grid cell. Three different independent variables were manipulated, two of which related to different kinds of complexity. Figural variety was manipulated in the same way as in Experiment 2, with three levels (2 different kinds of figures in the grid cells; 4 different kinds of figures; or all unique figures). Number of elements was manipulated across three levels by varying the number of cells within the grid (i.e., $5 \times 5,7 \times 7$ and $9 \times 9$ ). And finally, the grid size was manipulated across three levels by varying the dimensions of the overall grid frame $(6 \times 6 \mathrm{~cm}, 12 \times 12 \mathrm{~cm}$ and $18 \times 18 \mathrm{~cm})$ in order to 
explore the potential importance of size, which has sometimes been found to influence perceptual fluency, with larger figures being more perceptually fluent.

In sum, Experiment 3 involved a 2 (judgment condition: creativity vs. beauty) x 3 (figural variety) x 3 (number of elements) x 3 (grid size) design, with two repetitions (figures in different colours), for a total of 54 images that needed to be rated. Each participant rated the same series of 54 pictures twice, once for creativity and once for beauty. In other respects, the procedure was identical to that in Experiment 1.

\section{Results and Discussion}

Descriptive data for Experiment 3 are presented graphically in Figure 3. Repeatedmeasures ANOVA showed that the predicted interaction between complexity as measured by figural variety and judgment condition (creativity vs. beauty) was significant, $F(2,138)=74.46$, $p<.001, \eta_{p}{ }^{2}=0.52$. Likewise, the predicted interaction between complexity as measured by number of elements and judgment condition (creativity vs. beauty) was also significant, $F(2,138)$ $=9.72, p<.001, \eta_{p}^{2}=0.12$. The interaction between grid size and judgment condition (creativity vs. beauty) was not significant, $F(2,138)=0.31, p=.74, \eta_{p}^{2}<0.01$.

***Please insert Figure 3 about here $* * *$

The planned contrasts for the linear trend for creativity judgments for the two complexity measures of figural variety, $F(1,69)=119.56, p<.001, \eta_{p}{ }^{2}=0.63$, and number of elements, $F(1$, 69) $=32.79, p<.001, \eta_{p}{ }^{2}=0.32$, were highly significant and increasing ${ }^{4}$. The contrast for the

\footnotetext{
${ }^{4} \mathrm{We}$ did, in addition, find a non-planned quadratic trend (inverse U-shape) for the effect of number of elements on creativity judgments, $F(1,69)=4.19, p<.05, \eta_{p}^{2}=.06$, albeit with a much reduced effect size compared to the linear effect.
} 
linear trend for creativity judgments for grid size was slightly decreasing, but the effect was not significant, $F(1,69)=1.97, p=.17, \eta_{p}^{2}=0.03$.

The planned contrasts for the linear trend for beauty judgments for the two complexity measures of figural variety, $F(1,72)=0.49, p=.49, \eta^{2}=0.01$, and number of elements, $F(1$, $72)=1.13, p=.29, \eta_{p}{ }^{2}=0.02$, were not significant. However, the quadratic contrasts for the two complexity measures for beauty judgments showed a small but significant U-shaped quadratic effect for figural variety, $F(1,72)=8.21, p<.01, \eta_{p}{ }^{2}=0.10$, but a non-significant effect for number of elements $F(1,72)=0.01, p=.95, \eta_{p}^{2}<0.01$. The significant $\mathrm{U}$-shaped quadratic effect for figural variety is curious and difficult to interpret. Indeed, we wonder whether it is meaningful considering the far more striking linear effects that were observed for creativity judgments. We finally note that grid size showed no linear relation to beauty judgments, $F(1,72)$ $=0.05, p=.82, \eta_{p}^{2}<0.01$.

Whereas creativity judgments showed a consistent linearly increasing relation to increasing complexity - whether in the form of figural variety or number of elements - beauty did not show any linear trends in this experiment. The results for Experiment 3 align closely with those of Experiments 1 and 2 in once again demonstrating the existence of a clear differential effect of visual complexity on judgments of creativity and beauty (see Table 1). The results from manipulating visual complexity for creativity judgments in Experiments 1 to 3 align with the Cue-Attribution Theory and do not contradict the predictions generated from Creativity Theory. To examine whether the differential effect of complexity on judgment conditions generalizes to other sources of fluency, we added a new type of fluency source in the next experiment. 


\section{Experiment 4}

In order to establish firmly whether the "complex-is-creative" pattern identified in Experiments 1 to 3 is, in fact, a general interpretive reversal (fluent-is-beautiful vs. disfluent-iscreative) of experiencing fluency, as might be predicted from Cue-Attribution Theories, we decided to test a different type of fluency factor in addition to visual complexity, that is, figureground contrast. Hedonic-Marking Theory would predict that high contrast and low complexity would lead to higher beauty and possibly higher creativity evaluations. Creativity Theory would predict that higher complexity should result in increased creativity scores as in Experiments 1 to 3. The interesting case for Creativity Theory, however, is figure-ground contrast. If high figureground contrast is viewed as a sign of familiarity, and therefore a lack of novelty, we would expect that creativity judgments should decrease with higher contrast; if figure-ground contrast is viewed as a sign of usefulness, then we would expect that creativity judgments should increase with higher contrast.

A combination of higher creativity judgments for higher complexity and higher figureground contrast would have implications for fluency theory because in one case (i.e., complexity) lower fluency leads to higher judgments of creativity and in the other case (i.e., figure-ground contrast) higher fluency leads to higher judgments of creativity. This pattern of findings would contradict a central tenet of fluency theory, which posits that fluency is a global feeling, the consequences of which should be the same irrespective of the type of fluency source.

\section{Method}

Thirty undergraduates from Copenhagen Business School (25 female; mean age 20 years) were asked to judge images that varied in terms of figure-ground contrast and figural variety. Six images were selected from the three lowest complexity levels in Experiment 2 and were 
converted from colour into black and white. These images were then manipulated to create five levels of contrast per image, with evenly-spaced levels of illumination. This resulted in figures in the foreground that spanned the following grey-scale range: $10 \%, 30 \%, 50 \%, 70 \%$ and $90 \%$. Half of the images had a black background, and half had a white background. The images were based on the same stimuli used in Experiment 2 and were not pretested again, but it should be noted that it is possible that the additional manipulation of figure-ground contrast could affect the perceived complexity of the images (e.g., by reducing the saliency of visual details). Participants in Experiment 4 therefore judged 30 images in total for both creativity and beauty in a 2 (judgment condition: creativity vs. beauty) x 3 (visual complexity) x 5 (figure-ground contrast) design, with two repetitions. The procedure was otherwise the same as in Experiment 1.

\section{Results and Discussion}

A repeated-measures ANOVA showed that the three-way interaction between instruction condition, visual complexity, and figure-ground contrast was not significant $F(8,232)=1.78$, $p=.08, \eta_{p}^{2}=0.06$. As in Experiments 1 to 3, however, the interaction between visual complexity and judgment condition (creativity vs. beauty) was significant $F(2,58)=11.38, p<.001, \eta_{p}^{2}=$ 0.28. The planned contrast for visual complexity for the linear trend for creativity judgments, $F(1,29)=18.29, p<.001, \eta_{p}{ }^{2}=0.39$, was significant and increasing, as in Experiments 1 to 3. The linear contrast for beauty judgments displayed a small but significant increasing trend, $F(1$, 29) $=4.26, p<.05, \eta_{p}^{2}=0.13$, while the quadratic trend was not significant $F(1,29)=.01, p=$ $.92, \eta_{p}^{2}=0.00$.

Unlike the results from Experiments 1 to 3, the repeated-measures ANOVA revealed that the interaction between figure-ground contrast and judgment condition (creativity vs. beauty) was not significant, $F(4,116)<1.53, p=.20, \eta_{p}^{2}=0.05$ (see Figure 4). The planned contrasts for 
the linear trend for creativity judgments, $F(1,29)=12.94, p=.002, \eta_{p}{ }^{2}=0.31$ and for beauty judgments, $F(1,29)=18.01, p<.001, \eta_{p}^{2}=0.38$, were both significant and increasing (i.e., high contrast images are both creative and beautiful, whereas low contrast images are both uncreative and ugly).

***Please insert Figure 4 about here $* * *$

The results of Experiment 4 allow us to conclude that there are no differential effects on creativity and beauty judgments for figure-ground contrast, while (as in Experiments 1 to 3) such a differential effect is present for visual complexity. Instead, figure-ground contrast appears to influence creativity and beauty judgments in a similar, positive and linear manner (see Table 1)

Importantly, the results for the effect of figure-ground contrast on creativity support the notion that people see figure-ground contrast as a marker for quality because higher contrast led to higher judgments of creativity. The Hedonic-Marking Theory could explain this observation, too. However, the Hedonic-Marking Theory would also predict that complex stimuli would be judged as less creative, which was clearly not the case. We therefore conclude that respondents interpreted complexity in terms of originality and figure-ground contrast in terms of quality. This pattern of results falsifies the tenet that fluency is a global feeling from which people should draw the same inferences, independent of its source.

The results illustrate that different sources of fluency (figure-ground contrast vs. complexity) may differentially affect judgments of creativity even within the very same stimulus set. To examine this divergence of judgmental effects further, we decided to follow-up with two experiments that manipulated additional sources of fluency. In Experiment 5 we manipulated a fluency source that is associated with novelty perception (repeated exposure) and in Experiment 6 we manipulated image prototypicality. 


\section{Experiment 5}

Repeated exposure has been found to be related to subjective feelings of novelty. Based on our initial 3-way predictions, Hedonic-Marking Theory would expect that both creativity and beauty would increase with repeated exposure; the Cue-Attribution Theories might posit a differential effect on creativity and beauty of repeated exposure in so far as naïve beliefs about creativity and beauty differ with respect to the interpretation of subjective feelings of novelty. Finally, from the creativity literature we might expect that familiarity indicates a lack of

originality because the object is not novel to the perceiver. On the other hand, repeated exposure effects testify that familiarity increases the ease with which an object can be perceived. This efficiency could be seen as a sign of the quality or usefulness of the object. In line with the predictions in Experiment 4, we make two predictions regarding the effects of repeated exposure on creativity judgments. First, if familiarity is viewed as a lack of originality, then we would expect lower creativity judgments for repeatedly shown items. Second, and in contrast, if familiarity indicates usefulness, we would expect higher creativity judgments for repeatedly shown items.

\section{Method}

Forty-five participants from Copenhagen Business School (22 female; mean age 23 years) were asked to judge abstract (non-representational) art paintings that varied in terms of their repeated exposure frequency. Twenty-five paintings of abstract art were selected for this experiment. Following Bornstein and D’Agostino (1992), each picture was presented 0, 1, 5, 10 or 20 times before the participant was asked to rate it for beauty and for creativity. The images were counterbalanced in five series in a Latin-square design, ensuring that across every five participants each image had been presented in each of the five exposure frequency categories. 
The experimental procedure involved two stages. In Stage 1 participants were merely asked to view a number of images. Each image was preceded by a fixation cross at the centre of the screen for $2 \mathrm{~s}$, while the image itself was presented for $250 \mathrm{~ms}$. The images were divided into five exposure frequency categories with $0,1,5,10$ or 20 viewings in Stage 1, with 5 images in each exposure frequency category for a total of 180 exposures lasting approximately 6 minutes. The images were presented in random order. Following initial presentation in Stage 1 participants then progressed to Stage 2, where they were asked to rate the 25 images twice, once for beauty and once for creativity, with no time limit. The experiment thus entailed a 2 (judgment condition: creativity vs. beauty) x 5 (repeated exposure frequency categories) design, with 5 repetitions. Trials were randomized within each judgment category. Other aspects of the procedure were identical to Experiment 1.

\section{Results and Discussion}

Repeated-measures ANOVA revealed that the predicted interaction between exposure frequency and judgment condition (creativity vs. beauty) was significant, $F(4,176)=5.16, p<$ $.001, \eta_{p}{ }^{2}=0.10$ (see Figure 5 for descriptive data). The planned contrasts for the linear trend for creativity judgments, $F(1,44)=47.61, p<.001, \eta_{p}^{2}=0.52$, and for beauty judgments, $F(1,44)=$ 41.44, $p<.001, \eta_{p}^{2}=0.48$, were both significant and increasing with increasing levels of exposure frequency (see Table 1).

***Please insert Figure 5 about here***

Despite the significant linear trends for both creativity and beauty judgments, indicating that aesthetic liking increased as a function of increased exposure frequency, we acknowledge the existence of a significant interaction effect as well as the presence of non-linear (cubic) 
effects in the data ${ }^{5}$. The latter arise for both creativity and beauty judgments and occur at the extreme ends of exposure frequency (i.e., for either 20 repetitions or for 0 repetitions).

The results of Experiment 5 indicate that increased exposure frequency generally leads to higher judgments of both creativity and beauty. These findings align with both the HedonicMarking Theory and our predictions based on the creativity literature, but they challenge the hypothesis that an underlying experience of unfamiliarity with a stimulus can explain the differential effect of complexity on creativity and beauty judgments that was found in Experiments 1 to 4 . Note, however, that the results in the previous experiments clearly contradicted the hedonic-marking hypothesis because fluency stemming from lower complexity led to lower creativity judgments. To remain consistent, we believe that we have to explain the current result in terms of familiarity as an indicator for the usefulness facet of creativity.

\section{Experiment 6}

Arguing from the perspective of the creativity literature, stimulus prototypicality may be another case (as with visual complexity) where disfluency serves as an indicator of creativity. A low degree of prototypicality (disfluency) may be an indicator that a stimulus stands out distinctively relative to its category: that it is creative. The predictions in relation to prototypicality for all three theoretical frameworks are the same as for familiarity in the previous experiment. For creativity judgments, the Hedonic-Marking Theory predicts that prototypicality should increase judged creativity. The Cue-Attribution Theories predict that prototypicality

\footnotetext{
${ }^{5}$ As evident from the visual inspection of Figure 5, we found non-planned cubic effects for both creativity judgments, $F(1,44)=16.50, p<.001, \eta_{p}{ }^{2}=0.27$, and beauty judgments $F(1,44)=$ $34.69, p<.001, \eta_{p}^{2}=0.44$.
} 
should decrease judged creativity. Finally, Creativity Theory predicts that the fluency arising from prototypicality could be used as information in two ways: either as an indicator of item familiarity and hence lack of originality or else as an indicator of the usefulness of the item. In the former case, higher prototypicality would lead to lower judgments of creativity; in the latter case, higher prototypicality would lead higher judgments of creativity.

\section{Method}

Ninety participants from the Copenhagen Business School (36 female; mean age 22 years) were asked to judge simple blue/orange images. The stimuli followed ones developed by Gordon and Holyoak (1983, Experiment 2), and involved 10 x 10 matrices constructed out of blue and orange squares. The matrices were designed to be approximately $15 \mathrm{x} 15 \mathrm{~cm}$ in size.

Prototype stimuli (i.e., "standards") were constructed by randomly making half of the 100 squares of a matrix blue and the other half orange. Exposure stimuli were constructed by creating distorted versions of the standards, which involved reversing the colour (blue to orange; orange to blue) of a number of randomly selected squares. The number of squares that were changed in each distortion of the standard was determined by randomly sampling from the positive half of a normal distribution, with a mean of 0 and a standard deviation of 6 , and then adding 3 . This meant that the minimum distortion of standards seen by participants was $3 \%$. Given the properties of a normal distribution, $68 \%$ of the stimulus presentations involved distortions of less than $9 \%$, and $95 \%$ of the stimuli were distorted less than $15 \%$. A total of 30 standards were generated, each with 40 matching distortions. Each subject saw two of these standards.

The test stimuli consisted of distortions of $0 \%, 5 \%, 10 \%, 25 \%$ and $50 \%$ of each of the two standards used per participant during the experiment. The two stimuli with $0 \%$ distortions were, of course, the standards themselves. The stimuli with $50 \%$ distortion were random with 
respect to the standards from which they were generated (distortions greater than $50 \%$ begin to approach the mirror image of the standards).

The procedure involved an exposure phase, in which the participants were simply asked to view a set of stimuli, followed by a test phase, in which they were asked to rate a new set of stimuli for creativity and beauty. In the exposure phase each participant was exposed to the stimuli generated from two standards. The standard themselves where not presented in the exposure phase. The presentation of the stimuli was randomized and the instructions asked the participant to look at the patterns on the display screen. Each of the 80 patterns was presented for $3 \mathrm{~s}$, after which the screen went blank for $2 \mathrm{~s}$.

In the test phase, matched pairs of participants saw exactly the same 10 test stimuli in the same order giving rise to a 2 (judgment condition: creativity vs. beauty) x 5 (prototypicality) design, with 2 repetitions. Across pairs, random presentation orders were used. The participants rated the 10 stimuli twice, once for creativity and once for beauty, with the order of rating being counterbalanced (creativity first for 45 participants, and beauty first for another 45 participants). Each test stimulus was presented for $5 \mathrm{~s}$, after which participants rated it for either creativity or beauty using the VAS procedure as in Experiment 1. The next stimulus was presented $2 \mathrm{~s}$ after a participant had rated the previous one.

\section{Results and Discussion}

Repeated-measures ANOVA showed that the interaction between prototypicality and judgment condition (creativity vs. beauty) was not significant, $F(4,356)=1.08, p=.37, \eta_{p}^{2}=$ 0.01 (see Figure 6). The planned contrast for the linear trend was not significant for creativity judgments, $F(1,88)=0.04, p=.85, \eta_{p}^{2}<0.01$, but it was significant for beauty judgments, $F(1$, 
$88)=10.06, p=.003, \eta_{p}{ }^{2}=0.10$, with higher prototypicality being judged as more beautiful than lower prototypicality (see Table 1).

***Please insert Figure 6 about here***

The results indicate that unlike visual complexity (Experiments 1 to 4), prototypicality does not appear to serve as a perceptual indicator of creativity in the present experiment, challenging the initial predictions from Creativity Theory. However, we note that the images used for the experiment (10 x 10 blue/orange matrices) were perceptually difficult to differentiate. With the benefit of hindsight, it is perhaps possible that to achieve distinctiveness effects for prototypicality, the objects would need to be visually different to the degree that they are subsequently individually recognizable. The results also challenge the predictions from the Cue-Attribution Theories, while they are mainly in agreement with Hedonic-Marking theory. However, note again that the overall findings cannot be explained by the Hedonic-Marking Theory because fluency deriving from complexity led to lower creativity judgments in Experiments 1 to 4 .

Overall, the pattern of results for creativity across Experiments 1 to 6 demonstrates that some perceptual fluency indicators feed into creativity in a high-fluency-is-creative manner (i.e., figure-ground contrast and mere exposure), while visual complexity stands out as driving a consistent and dominant reversal of the direction of this effect (i.e., disfluency-is-creative). This result may reflect differing interpretation of fluency experiences when they stem from different sources; disfluency stemming from complexity is interpreted in terms of originality whereas fluency stemming from contrast or familiarity is interpreted in terms of usefulness. Therefore, both disfluency (from complexity) and fluency (from figure-ground contrast and repeated exposure) can be judged to be more creative. Conversely, the results for beauty replicate past 
high-fluency-is-beautiful findings, except for visual complexity, which displayed a complex pattern of effects on beauty (in alignment with past findings).

\section{Experiment 7}

To make sense of the pattern of findings for creativity judgments, we speculate that such judgments may, in the absence of perceptual indicators of objective distinctiveness, instead rely on hedonically marked subjective feelings of fluency (in alignment with the Hedonic-Marking Theory). However, in the presence of indicators of objective distinctiveness (e.g., visual complexity), the strength of these disfluent-is-creative indicators will lead to an override of fluency effects that are not related to objective distinctiveness. Given that creativity judgments are closely tied to objective attributions (rather than subjective experiences), we hypothesized that by increasing the saliency of visual complexity in a stimulus set, creativity judgments (relative to beauty judgments) should subsequently rely less on perceptual fluency cues unrelated to objective distinctiveness (such as figure-ground contrast).

A simple way of testing this assumption is to repeat two of our experiments in close succession, by first engaging participants in a replication of Experiment 2 (manipulating visual complexity), whereby they should become attuned to the underlying complexity dimension, followed by undertaking a replication of Experiment 4 (manipulating figure-ground contrast and visual complexity). We hypothesized that for creativity judgments (but not beauty judgments), the increased saliency of visual complexity stemming from first undergoing Experiment 2 should lead to an override of the fluency effect arising from figure-ground contrast. Participants rating creativity should thus rely mainly on visual complexity rather than figure-ground contrast, which would oppose the findings reported in Experiment 4. For beauty ratings, we expected a 
replication of the findings in Experiment 4, as participants should still rely on figure-ground contrast even in the context of increased complexity salience.

\section{Method}

Sixty-nine undergraduates from the Copenhagen Business School (48 female; mean age 24 years) took part in the study. As we aimed to examine the effects of increased complexity salience across experiments and instruction conditions, 34 participants rated only creativity, and 35 rated only beauty. Participants first took part in a replication of Experiment 2, followed immediately by a replication of Experiment 4 (rating in both cases only for either creativity or beauty). In other respects, the procedure was the same as Experiments 2 and 4.

\section{Results and Discussion}

For the first part of the experiment, which aimed to increase the saliency of visual complexity, replicating Experiment 2, a repeated-measures ANOVA on the judgment data revealed that the predicted interaction between visual complexity and judgment condition (creativity vs. beauty) was significant, $F(7,469)=48.63, p<.001, \eta_{p}{ }^{2}=0.42$. The planned contrast for the linear trend for creativity judgments was highly significant and increasing, $F(1$, $33)=87.33, p<.001, \eta_{p}^{2}=0.73$, whereas the planned contrast for the linear trend for beauty judgments, was significant and decreasing, $F(1,34)=21.84, p<.001, \eta_{p}^{2}=0.39$, as was the quadratic trend (inverse-U) for beauty, $F(1,34)=8.78, p<.01, \eta_{p}^{2}=0.21$ (see Table 1$)$.

For the second part of the experiment, where the saliency of visual complexity had been increased, a repeated-measures ANOVA showed that the three-way interaction between instruction condition, visual complexity, and figure-ground contrast was not significant, $F(8$, 536) $=0.40, p=.92, \eta_{p}{ }^{2}=0.01$. However, the analysis revealed the predicted significant interactions between judgment condition (creativity vs. beauty) and figure-ground contrast, $F(4$, $268)=3.64, p=.007, \eta_{p}^{2}=0.05$, and between judgment condition and figural variety, $F(2,134)$ 
$=9.12, p<.001, \eta_{p}{ }^{2}=0.12$ (see Figure $4-$ which also allows for direct comparison to

Experiment 4). For creativity judgments, the linear trend for figure-ground contrast was not significant, $F(1,33)=0.36, p=.55, \eta_{p}^{2}=0.01$, while figural variety ${ }^{6}$ had a significant increasing effect, $F(1,33)=16.94, p<.001, \eta_{p}^{2}=0.34$ (see Table 1$)$, with no interaction between the two sources of fluency, $F(1,33)=0.54, p=.47, \eta_{p}{ }^{2}=0.01$. Conversely, for beauty judgments, the linear trend for figure-ground contrast was significant and increasing, $F(1,34)=10.00, p=.003$, $\eta_{p}{ }^{2}=0.23$, while figural variety had no significant linear effect, $F(1,34)=0.22, p=.65, \eta_{p}^{2}=$ 0.01 , nor quadratic tend, $F(1,34)=.07, p=.79, \eta_{p}{ }^{2}=0.00$ (see Table 1 ), still with no interaction between the two determinants of fluency, $F(1,34)=0.22, p=.64, \eta_{p}^{2}=0.01$.

In order to test specifically for the hypothesis that the increased visual complexity saliency provided by having the participants first go through Experiment 2 would override, and thus lead to a decrease in the reliance on, figure-ground contrast for creativity (but not beauty), we examined the difference between the responses from Experiment 4 and 7. For beauty judgments, repeated-measures ANOVA showed no significant interactions between experimental condition (Experiments 4 vs. 7) and figure-ground contrast, $F(4,252)=0.47, p=.76, \eta p^{2}=0.01$, or between experimental condition and visual complexity, $F(2,126)=0.76, p=.47, \eta_{p}^{2}=0.01$. However, and as expected, for creativity judgments, repeated-measures ANOVA showed significant interactions between experimental condition (Experiments 4 vs. 7) and figure-ground contrast, $F(4,248)=3.66, p=.007, \eta_{p}^{2}=0.06$, but not between experimental condition and

\footnotetext{
${ }^{6} \mathrm{We}$ did, in addition, find a non-planned quadratic effect (inverse U-shaped) for figural variety on creativity judgments, $F(1,33)=4.60, p<.05, \eta_{p}{ }^{2}=0.12$, albeit with a reduced effect size compared to the liner trend.
} 
visual complexity, $F(2,124)=2.65, p=.08, \eta_{p}^{2}=0.04$, although the latter results were borderline significant.

The results replicated Experiment 2 for visual complexity. Crucially, however, the increased saliency of visual complexity induced by the replication of Experiment 2 influenced participants' judgments of creativity in the replication of Experiment 4: participants switched to relying only on visual complexity, and not on figure-ground contrast. Conversely, participants' judgments of beauty were unaffected by the increased saliency of visual complexity, and they still (as in Experiment 4) relied mainly on figure-ground contrast for their ratings.

The results lend support to the hypothesis that creativity judgments are strongly affected by objective distinctiveness indicators (in a disfluent-is-creative direction) which, if made salient, may override other fluent-is-creative attributions. Specifically, we assume that by making complexity and thus originality salient then the use of fluency as information for the originality of objects cancels out the effect of fluency as an indicator of usefulness, as observed in Experiment 4.

\section{General Discussion}

In the present series of experiments, we tested the effects of perceptual fluency on two distinct forms of aesthetic judgments: creativity and beauty. Our overarching prediction for beauty judgments was that they would display a standard higher-fluency-liking relation, albeit possibly with an inverted $\mathrm{U}$-shaped relation in the case of visual complexity. We based our predictions for how perceptual fluency might affect creativity judgments on theories of perceptual fluency and creativity, arguing for at least three different possible outcomes. First, from Reber et al. (2004a), we argued that perceptual fluency experiences might be hedonically marked, leading to similar positive judgments of creativity and beauty (i.e., high-fluency-is- 
creative). Second, from Cue-Attribution Theories (e.g., Alter \& Oppenheimer, 2009) we argued that creativity judgments might be based on naïve beliefs that perceptual disfluency is an indicator of stimulus novelty, or that such judgments might relate centrally to arousal, interest or growth, which (for different theoretical reasons) may converge on disfluent-is-creative attributions. Third, from Creativity Theory, we argued that only perceptual indicators of object distinctiveness (e.g., visual complexity) should serve as indicators of originality and therefore creativity (i.e., disfluent-is-original and therefore disfluent-is-creative). However, fluency from other sources, such as figure-ground contrast and repeated exposure, might be interpreted in terms of usefulness or quality and thus creativity (i.e., fluent-is useful and therefore fluent-iscreative).

We tested these overarching predictions across seven experiments that manipulated four different determinants of fluency (i.e., visual complexity, repeated exposure, prototypicality and contrast) and three different instantiations of visual complexity. Across our reported experiments we found fluency effects for both creativity and beauty in the majority of cases. We also found that the particular fluency sources served to modulate whether beauty and creativity judgments acted in concord or whether they displayed opposing response patterns. We therefore show, for the first time, that creativity ratings are influenced by perceptual fluency across almost all fluency sources, albeit with a reversal in the directionality of observed effects on judgment for the key dimension of visual complexity. Most importantly, we observe that an aesthetic judgment type (i.e., creativity) may display a high-fluency-is-creative association for some sources of fluency (e.g., repeated exposure and figure-ground contrast), but the reverse disfluency-is-creative association for another source of fluency (i.e., visual complexity). To our knowledge, only one prior study (Silva et al., 2016) has shown dissociations between different 
sources of fluency (i.e., repeated exposure vs. color contrast) on learned reversals for judgments of truth.

In alignment with Hedonic-Marking Theory, we first note that the generally positive effects of perceptual fluency on beauty judgments that are well established in prior research were observed to be replicable in the present series of experiments. That is: perceptual fluency deriving from repeated stimulus exposure, from higher level of prototypicality and from elevated figure-ground contrast, all led to linear increases in beauty judgments. Interestingly, for these same fluency dimensions, creativity judgments did not differ significantly from beauty judgments, and for repeated exposure and figure-ground contrast these judgments displayed the same linear increase, indicating that experienced fluency leads to increasing ratings of both beauty and creativity.

This latter finding documents for the first time that creativity judgments are subject to fluency effects, and furthermore, these fluency effects can track the hedonic high-fluency-iscreative link. For repeated exposure and figure-ground contrast the effect was linear and highly significant. For prototypicality, beauty and creativity judgments did not deviate significantly from each other, but only beauty displayed a significant linear fluency effect; prototypicality had no significant effect on creativity judgments. It seems that experienced fluency can feed positively into judgments of creativity, which surprisingly may suggest that higher feelings of familiarity (and lower subjective feelings of novelty) may in some cases (notably repeated exposure) contribute positively to creativity judgments.

A second observation pertains to the special case of visual complexity. Our findings clearly demonstrate that fluency experiences deriving from this particular source should be viewed as being a rather special member of what Alter and Oppenheimer (2009) have poignantly 
referred to as the "tribe" of fluency feelings. Indeed, with a fitting theoretical twist, whilst the explanation for the influence on judgment of most fluency sources proved to be fairly simple and parsimonious (i.e., ease of processing leads to judgments of both beauty and creativity), explaining the effects of visual complexity on aesthetic judgments is somewhat more theoretically challenging. In terms of our findings, across five experiments (using Picasso paintings, and simple experimental figures) we observed a consistent, strong, linear positive relation between visual complexity and judgments of creativity. In our experiments a higher degree of figural variety, an increased number of elements, and higher subjective ratings of complexity, all predicted creativity judgments positively and linearly, with large effect sizes. These reliable findings are in contrast with the impact of visual complexity on beauty judgments, where - in line with past, mixed findings - we observed an inverted U-shaped relation in Experiment 1, a linear negative relation in Experiment 2, and mainly null relations in Experiment 3,4 and 7.

One piece of evidence for Creativity Theory is the malleability of the interpretation of fluency. The strong association between originality and judgments of creativity implies that visual complexity can effectively override other sources of fluency in affecting creativity scores. This was shown in Experiment 7, where increasing the visual saliency of complexity led participants to rely only on visual complexity (not figure-ground contrast) in their creativity ratings. Taken together, we contend that our findings concerning the differential effects of visual complexity and other sources of fluency on creativity judgments cannot be explained by either Hedonic-Marking Theory or by Cue-Attribution Theories but fit better with Creativity Theory, which distinguishes two facets of creativity, that is, originality and usefulness. Note that positive 
evidence for Creativity Theory is relatively weak; it is supported by the exclusion of the two other theories that would predict uniform effects for all sources of fluency.

The explanation for our data seems to challenge the central tenet of fluency theory, which views a fluency experience as a global feeling that can arise from various sources such that fluency effects should not depend on the specific source of this metacognitive feeling. In line with research by Silva et al. (2016), our observations seem to suggest that this tenet may not hold. The best explanation we can offer from the current findings, based on Creativity Theory, is that fluency source manipulations arising from complexity are interpreted as an indicator of originality whereas fluency source manipulations arising from figure-ground contrast and repeated exposure are interpreted as indicators of usefulness. Prototypicality did not show any effect, either because it neither indicates originality nor usefulness, or because the two interpretations cancel each other out.

To establish and test these aforementioned conjectures more firmly, future research would need to design a study that separately measures: (1) the source variables that make processing easy or difficult, (2) the affective response (i.e., the fluency experience) that is elicited by the source variables; and (3) the derived inferences on judgments of originality and usefulness that arise from ease or difficulty of processing, through the application of lay theories. In the present set of experiments, we acknowledge that we do not have independent evidence that complexity is interpreted in terms of originality whereas figure-ground contrast and repeated exposure are interpreted in terms of usefulness.

Overall, when considering both beauty and creativity judgments, we suggest that our findings both challenge and inform fluency models that claim a unified tribe of fluency feelings that are hedonically marked (e.g., Reber et al., 2004a) or that may be subject to attribution 
through the application of naïve theories (e.g., Alter \& Oppenheimer, 2009). Visual complexity, in particular, seems to stand out as a special source of fluency experience, being interpreted as aesthetically positive or negative, depending on the nature of the aesthetic judgment task.

Importantly, people do not uniformly assess high fluency as related negatively, or positively, to creativity. Rather, the interpretation of high perceptual fluency in terms of the facets of creativity - originality and usefulness - seems to vary with the nature of the source of fluency.

\section{Limitations and Future Research Directions}

The present set of experiments utilized a variety of images that to varying degrees might invoke expectations of rating art as opposed to non-art. For example, Experiments 1 and 5 made use of actual pictorial art, while the remaining experiments relied on the manipulation of simple visual figures. Although we do not believe that the distinction between art and non-art images can explain our results (since visual complexity and other sources of fluency were tested using both art and non-art images with similar results) we nevertheless acknowledge the potential importance of this contextual prime. Indeed, it may be the case that art images (more than nonart images) invoke the importance of considering aesthetic appreciation forms related to domain history, and thus creativity, which might conceptually conflate creativity and beauty judgments in art evaluation. We concede that more research is needed to replicate our findings in more controlled art versus non-art conditions.

In our studies, the Creativity Theory was supported by the exclusion of its competitors, Hedonic-Marking theory and Cue-Attribution Theory. It would be valuable for future research to attempt the replication of the present findings with additional creativity facets being tested across multiple items. This would allow for further direct tests of whether visual complexity and other sources of fluency influence originality (or novelty) perception, feature-based object usefulness 
(or value) perception, or both, which would further inform how and why visual distinctiveness and familiarity affect creativity judgments. Such studies would enable researchers to gather more thorough evidence in favour of predictions based on the Creativity Theory.

\section{References}

Alter, A. L., \& Oppenheimer, D. M. (2009). Uniting the tribes of fluency to form a metacognitive nation. Personality \& Social Psychology Review, 13, 219-235.

Armstrong, T., \& Detweiler-Bedell, B. (2008). Beauty as an emotion: The exhilarating prospect of mastering a challenging world. Review of General Psychology, 12, 305-329. doi: $10.1037 / \mathrm{a} 0012558$

Ball, L. J., Threadgold, E., Marsh, J. E., \& Christensen, B. T. (2018). The effects of stimulus complexity and conceptual fluency on aesthetic judgments of abstract art: Evidence for a default-interventionist account. Metaphor \& Symbol, 33, 235-252.

Bar, M., \& Neta, M. (2006). Humans prefer curved visual objects. Psychological Science, 17, $645-648$.

Berlyne, D. E. (1958). The influence of complexity and novelty in visual figures on orienting response. Journal of Experimental Psychology, 55, 289-296.

Berlyne, D. E. (1971). Aesthetics and psychobiology. New York, NY: Appleton-Century-Crofts.

Bertamini, M., Makin, A., \& Rampone, G. (2013). Implicit association of symmetry with positive valence, high arousal and simplicity. i-Perception, 4, 317-327.

Bornstein, R. F. (1989). Exposure and affect: Overview and meta-analysis of research, 19681987. Psychological Bulletin, 106, 265-289. 
Bornstein, R. F., \& D'Agostino, P. R. (1992). Stimulus recognition and the mere exposure effect. Journal of Personality \& Social Psychology, 63, 545-552.

Briñol, P., Petty, R. E., \& Tormala, Z. L. (2006). The malleable meaning of subjective ease. Psychological Science, 17, 200-206.

Bullot, N. J., \& Reber, R. (2013). The artful mind meets art history: Toward a psycho-historical framework for the science of art appreciation. Behavioral \& Brain Sciences, 36, 123-137.

Cho, H. \& Schwarz, N. (2006). If I don't understand it, it must be new: Processing fluency and perceived product innovativeness. In C. Pechmann \& L. Price (Eds.), Advances in consumer research, Volume 33 (pp. 319-320). Duluth, MN: Association for Consumer Research.

Christensen, B. T., Kristensen, T., \& Reber, R. (2015). Contributions of perceived creativity and beauty to willingness-to-pay for design products. International Journal of Design Creativity \& Innovation, 3, 164-176.

Clore, G. L. (1992). Cognitive phenomenology: Feelings and the construction of judgment. In L. L. Martin \& A. Tesser (Eds.), The construction of social judgments (pp. 133-163). Hillsdale, NJ: Erlbaum.

Cropley, D., \& Cropley, A. (2008). Elements of a universal aesthetic of creativity. Psychology of Aesthetics, Creativity, \& the Arts, 2, 155-161.

Diedrich, J., Benedek, M., Jauk, E., \& Neubauer, A. C. (2015). Are creative ideas novel and useful? Psychology of Aesthetics, Creativity, \& the Arts, 9, 35-40.

Eisenman, R., \& Rappaport, J. (1967). Complexity preference and semantic differential ratings of complexity-simplicity and symmetry-asymmetry. Psychonomic Science, 7, 147-148. 
Eysenck, H. J. (1942). The experimental study of the "good gestalt": A new approach. Psychological Review, 49, 344-364.

Flavell, J. H. (1979). Metacognition and cognitive monitoring: A new area of cognitivedevelopmental inquiry. American Psychologist, 34, 906-911.

Forster, M., Leder, H., \& Ansorge, U. (2013). It felt fluent, and I liked it: Subjective feeling of fluency rather than objective fluency determines liking. Emotion, 13, 280-289.

Geert, E. V., \& Wagemans, J. (in press). Order, complexity and aesthetic appreciation. Psychology of Aesthetics, Creativity, \& the Arts.

Gillebaart, M., Förster, J., \& Rotteveel, M. (2012). Mere exposure revisited: The influence of growth versus security cues on evaluations of novel and familiar stimuli. Journal of Experimental Psychology: General, 141, 699-714.

Gordon, P. C., \& Holyoak, K. J. (1983). Implicit learning and generalization of the "mere exposure" effect. Journal of Personality \& Social Psychology, 45, 492-500.

Graf, L. K. M., \& Landwehr, J. R. (2015). A dual-process perspective on fluency-based aesthetics: The Pleasure-Interest Model of Aesthetic Liking. Personality \& Social Psychology Review, 19, 395-410.

Hagtvedt, H., Hagtvedt, R., \& Patrick, V. M. (2008). The perception and evaluation of visual art. Empirical Studies of the Arts, 26, 197-218.

Horn, D., \& Salvendy, G. (2009). Measuring consumer perception of product creativity: Impact on satisfaction and purchasability. Human Factors \& Ergonomics in Manufacturing, 19, $223-240$.

Humphrey, D. (1997). Preferences in symmetries and symmetries in drawings: Asymmetries between ages and sexes. Empirical Studies of the Arts, 15, 41-60. 
Jacoby, L. L. (1983). Perceptual enhancement: Persistent effects of an experience. Journal of Experimental Psychology: Learning, Memory, \& Cognition, 9, 21-38.

Jakesch M., Leder H., \& Forster M. (2013). Image ambiguity and fluency. PLoS ONE, 8, e74084. doi: 10.1371/journal.pone

Joye, Y., Steg, L., Ünal, A. B., \& Pals, R. (2016). When complex is easy on the mind: Internal repetition of visual Information in complex objects is a source of perceptual fluency. Journal of Experimental Psychology: Human Perception \& Performance, 42, 103-114.

Keltner, D., \& Haidt, J. (2003). Approaching awe, a moral, spiritual, and aesthetic emotion. Cognition \& Emotion, 17, 297-314.

Koriat, A. (1993). How do we know that we know? The accessibility model of the feeling of knowing. Psychological Review, 100, 609-639. doi: 10.1037/0033-295X.100.4.609

Kozbelt, A. (2004). Originality and technical skill as components of artistic quality. Empirical Studies of the Arts, 22, 157-170.

Labroo, A. A., \& Pocheptsova, A. (2016). Metacognition and consumer judgment: fluency is pleasant but disfluency ignites interest. Current Opinion in Psychology, 10, 154-159.

Marin, M. M., \& Leder, H. (2013). Examining complexity across domains: Relating subjective and objective measures of affective environmental scenes, paintings and music. PLoS ONE, 8, e72412.

Martindale, C., Moore, K., \& Borkum, J. (1990). Aesthetic preference: Anomalous findings for Berlyne's psychobiological theory. American Journal of Psychology, 103, 53-80.

Mayer, R. E. (1999). Fifty years of creativity research. In R. J. Sternberg (Ed.), Handbook of creativity (pp. 449-460). Cambridge, UK: Cambridge University Press. 
Munsinger, H., \& Kessen, W. (1964). Uncertainty, structure, and preference. Psychological Monographs, 78, Whole No. 586.

Oppenheimer, D. M., \& Frank, M. C. (2008). A rose in any other font would not smell as sweet: Effects of perceptual fluency on categorization. Cognition, 106, 1178-1194. doi: 10.1016/j.cognition.2007.05.010

O'Quin, K., \& Besemer, S. (1989). The development, reliability, and validity of the revised creative product semantic scale. Creativity Research Journal, 2, 267-278.

Reber, R., Schwarz, N., \& Winkielman, P. (2004a). Processing fluency and aesthetic pleasure: Is beauty in the perceiver's processing experience? Personality \& Social Psychology Review, $8,364-382$.

Reber, R., Winkielman, P., \& Schwarz, N. (1998). Effects of perceptual fluency on affective judgments. Psychological Science, 9, 45-48.

Reber, R., Wurtz, P., \& Zimmermann, T. D. (2004b). Exploring “fringe” consciousness: The subjective experience of perceptual fluency and its objective bases. Consciousness \& Cognition, 13, 47-60. doi: 10.1016/S1053-8100(03)00049-7

Runco, M. A., \& Charles, R. E. (1993). Judgments of originality and appropriateness as predictors of creativity. Personality \& Individual Differences, 15, 537-546.

Runco, M. A., \& Jaeger, G. J. (2012). The standard definition of creativity. Creativity Research Journal, 24, 92-96.

Schwarz, N. (1998). Accessible content and accessibility experiences: The interplay of declarative and experiential information in judgment. Personality \& Social Psychology Review, 2, 87-99. 
Schwarz, N. (2004). Metacognitive experiences in consumer judgment and decision making. Journal of Consumer Psychology, 14, 332-348.

Schwarz, N. (2010). Meaning in context: Metacognitive experiences. In B. Mesquita, L. F. Barrett, \& E. R. Smith (Eds.), The mind in context (pp. 105-125). New York: Guilford. Schwarz, N. (2011). Feelings-as-information theory. P. Van Lange, A. Kruglanski, \& E. T. Higgins (Eds.), Handbook of theories of social psychology (pp. 289-308). London: Sage Publications Ltd.

Schwarz, N. \& Clore, G. L. (2007). Feelings and phenomenal experiences. In E. T. Higgins \& A. Kruglanski (Eds.), Social psychology. A handbook of basic principles. 2nd Ed. (pp. 385407). New York: Guilford Press.

Silva, R. R., Garcia-Marques, T., \& Mello, J. (2016). The differential effects of fluency due to repetition and fluency due to color contrast on judgments of truth. Psychological Research, 80, 821-837.

Stein, M. I. (1953). Creativity and culture. Journal of Psychology, 36, 311-322.

Topolinski, S., Erle, T. M., \& Reber, R. (2015). Necker’s smile: Immediate affective consequences of early perceptual processes. Cognition, 140, 1-13.

Topolinski, S., \& Strack, F. (2009). The analysis of intuition: Processing fluency and affect in judgements of semantic coherence. Cognition \& Emotion, 23, 1465-1503. doi: $10.1080 / 02699930802420745$

Unkelbach, C. (2006). The learned interpretation of cognitive fluency. Psychological Science, 17, 339-345.

Vitz, P. C. (1966). Affect as a function of stimulus variation. Journal of Experimental Psychology, 71, 74-79. 
Whittlesea, B. W. A. (1993). Illusions of familiarity. Journal of Experimental Psychology: Learning, Memory, \& Cognition, 19, 1235-1253. doi: 10.1037/0278-7393.19.6.1235

Winkielman, P., \& Cacioppo, J. T. (2001). Mind at ease puts a smile on the face:

Psychophysiological evidence that processing facilitation elicits positive affect. Journal of Personality \& Social Psychology, 81, 989-1000. doi: 10.1037/0022-3514.81.6.989

Winkielman, P., Halberstadt, J., Fazendeiro, T., \& Catty, S. (2006). Prototypes are attractive because they are easy on the mind. Psychological Science, 17, 799-806.

Winkielman, P., Schwarz, N., Fazendeiro, T., \& Reber, R. (2003). The hedonic marking of processing fluency: Implications for evaluative judgment. In J. Musch \& K. C. Klauer (Eds.), The psychology of evaluation: Affective processes in cognition and emotion (pp. 189-217). Mahwah, NJ: Erlbaum.

Young, M. E. \& Racey, D. (2009). Judgments of creativity as a function of visual stimulus variability. Empirical Studies of the Arts, 27, 89-107.

Zajonc, R. B. (1968). Attitudinal effects of mere exposure. Journal of Personality \& Social Psychology, 9, 1-27.

Zeng, L., Salvendy, G., \& Zhang, M. (2009). Factor structure of web site creativity. Computers in Human Behavior, 25, 568-577.

Zhou, J., Wang, X. M., Song, L. J., \& Wu, J. (2017). Is it new? Personal and contextual influences on perceptions of novelty and creativity. Journal of Applied Psychology, 102, 180-202.

Ziv, N., \& Keydar, E. (2009). The relationship between creative potential, aesthetic response to music, and musical preferences. Creativity Research Journal, 21, 125-133. 
Table 1

Overview of the direction of the effects of the planned contrasts for fluency manipulations (ranging from fluent to disfluent) on judgments of creativity and beauty across Experiments 1 to 7

\begin{tabular}{|c|c|c|c|c|c|}
\hline \multirow[b]{3}{*}{ Exp. } & \multirow[b]{3}{*}{ Fluency manipulation } & & \multicolumn{3}{|c|}{ Judgment task } \\
\hline & & & \multirow{2}{*}{$\begin{array}{c}\text { Creativity } \\
\text { Linear } \\
\end{array}$} & \multicolumn{2}{|c|}{ Beauty } \\
\hline & & $\mathbf{N}$ & & Linear & Quadratic \\
\hline 1 & Visual complexity & 63 & & n.s. & \\
\hline 2 & Visual complexity & 45 & & & n.s. \\
\hline 3 & Visual complexity (number) & 73 & & n.s. & \\
\hline 3 & Visual complexity (variety) & 73 & & n.s. & n.s. \\
\hline 4 & Figure-ground contrast & 30 & & & \\
\hline 4 & Visual complexity & 30 & & & n.s. \\
\hline 5 & Repeated exposure & 45 & & & \\
\hline 6 & Prototypicality & 90 & n.s. & & \\
\hline 7 & Visual complexity (part I) & 69 & & & \\
\hline 7 & Figure-ground contrast & 69 & n.s. & & \\
\hline 7 & Visual complexity (part II) & 69 & & n.s. & n.s. \\
\hline
\end{tabular}




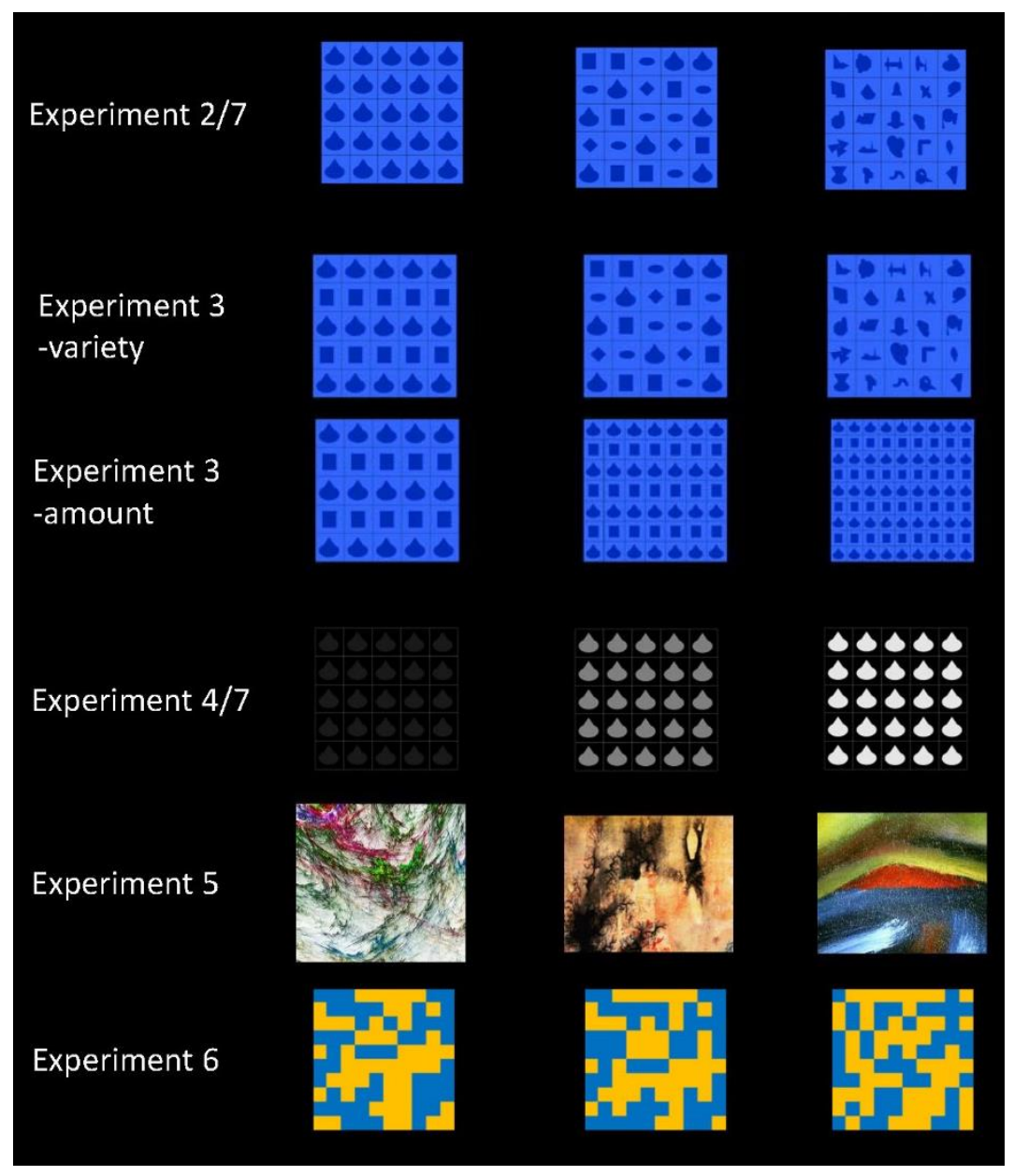

Figure 1. Examples of the stimuli used in Experiments 2 to 7. Note that Experiment 1 utilised Picasso paintings, which are not represented in the figure for reasons of copyright. 


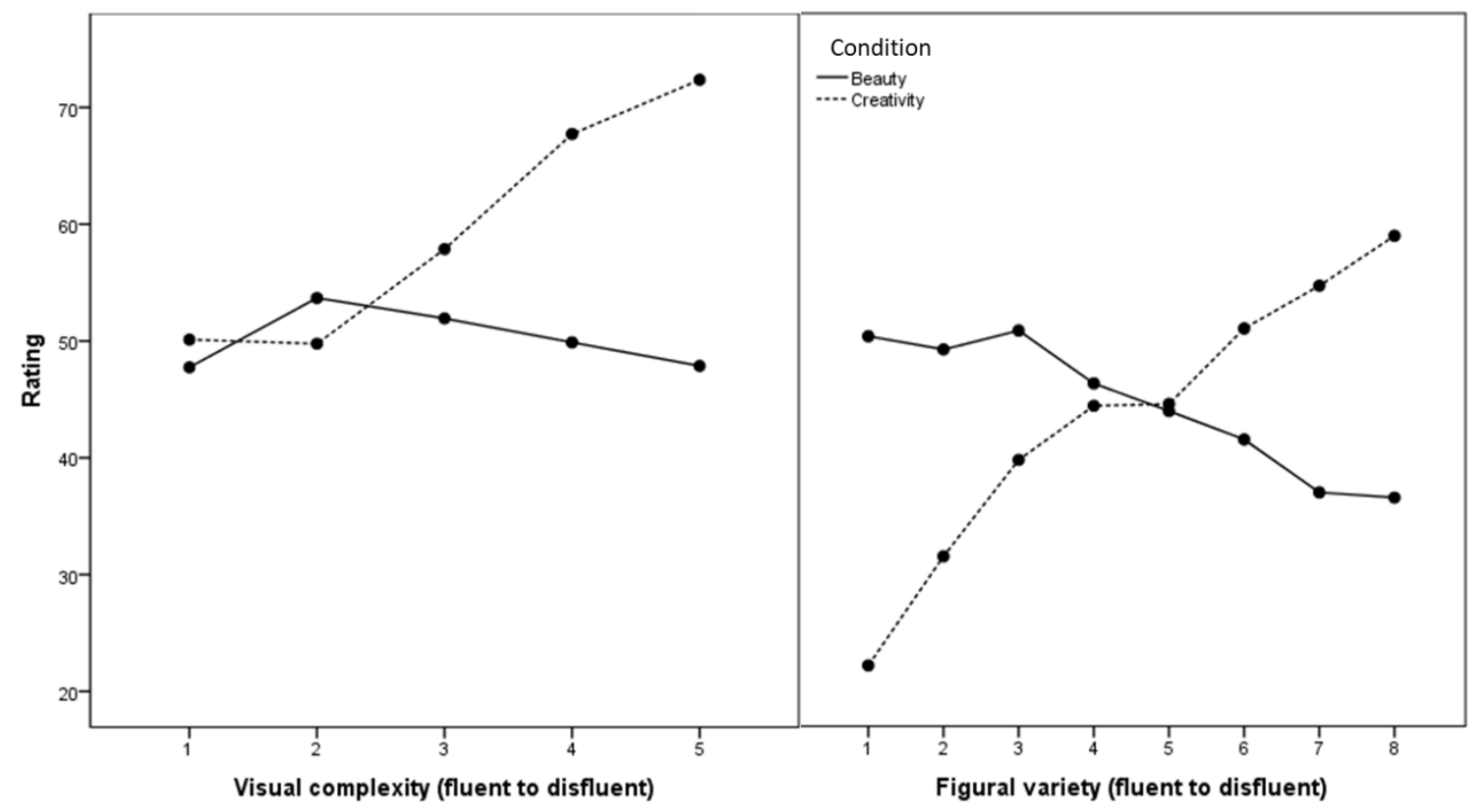

Figure 2. Ratings for creativity and beauty as a function of visual complexity in Experiment 1 (left panel) and as a function of figural variety in Experiment 2 (right panel). 


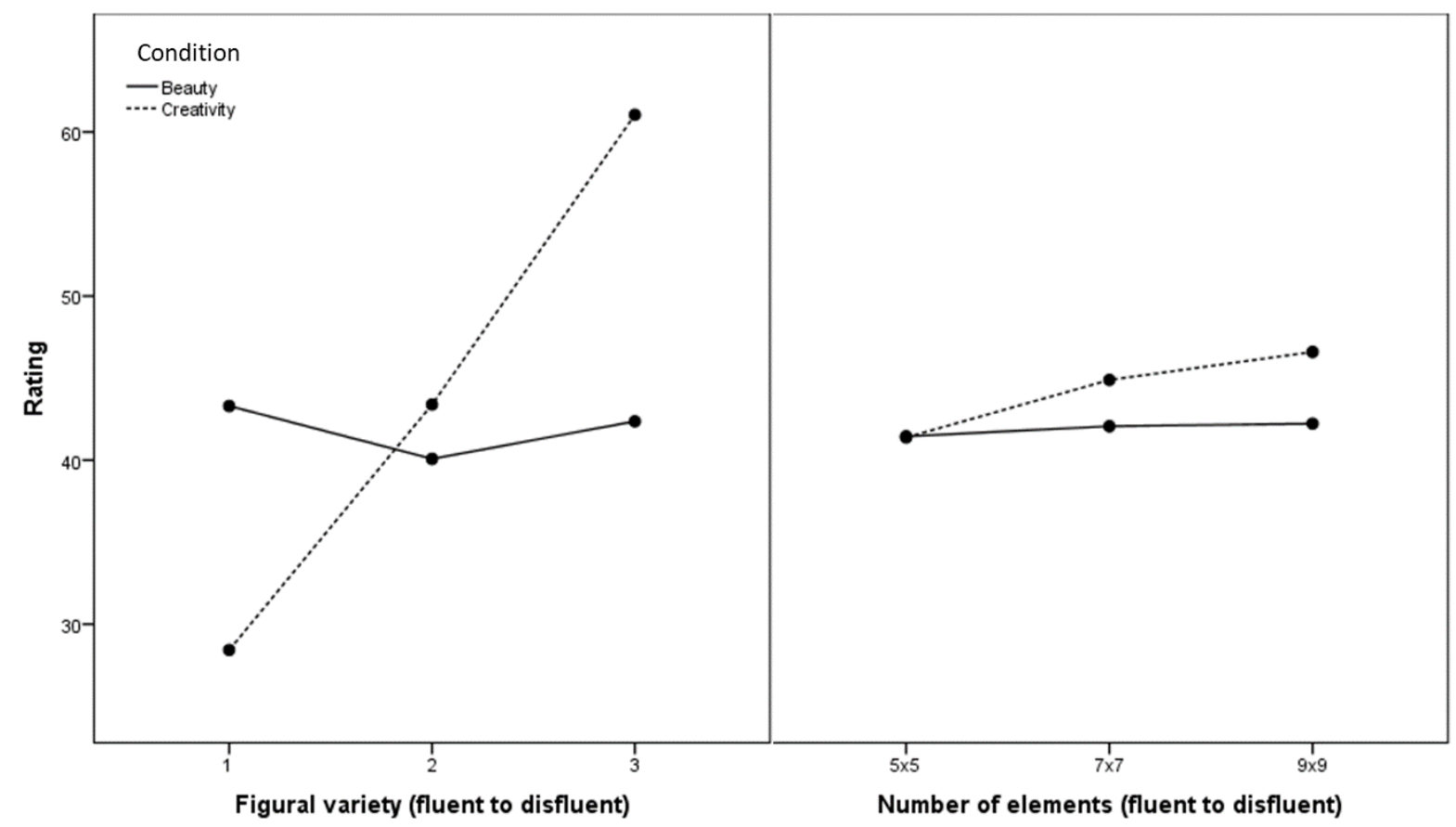

Figure 3. Ratings for creativity and beauty as a function of figural variety (left panel) and as a function of number of elements (right panel) in Experiment 3. 


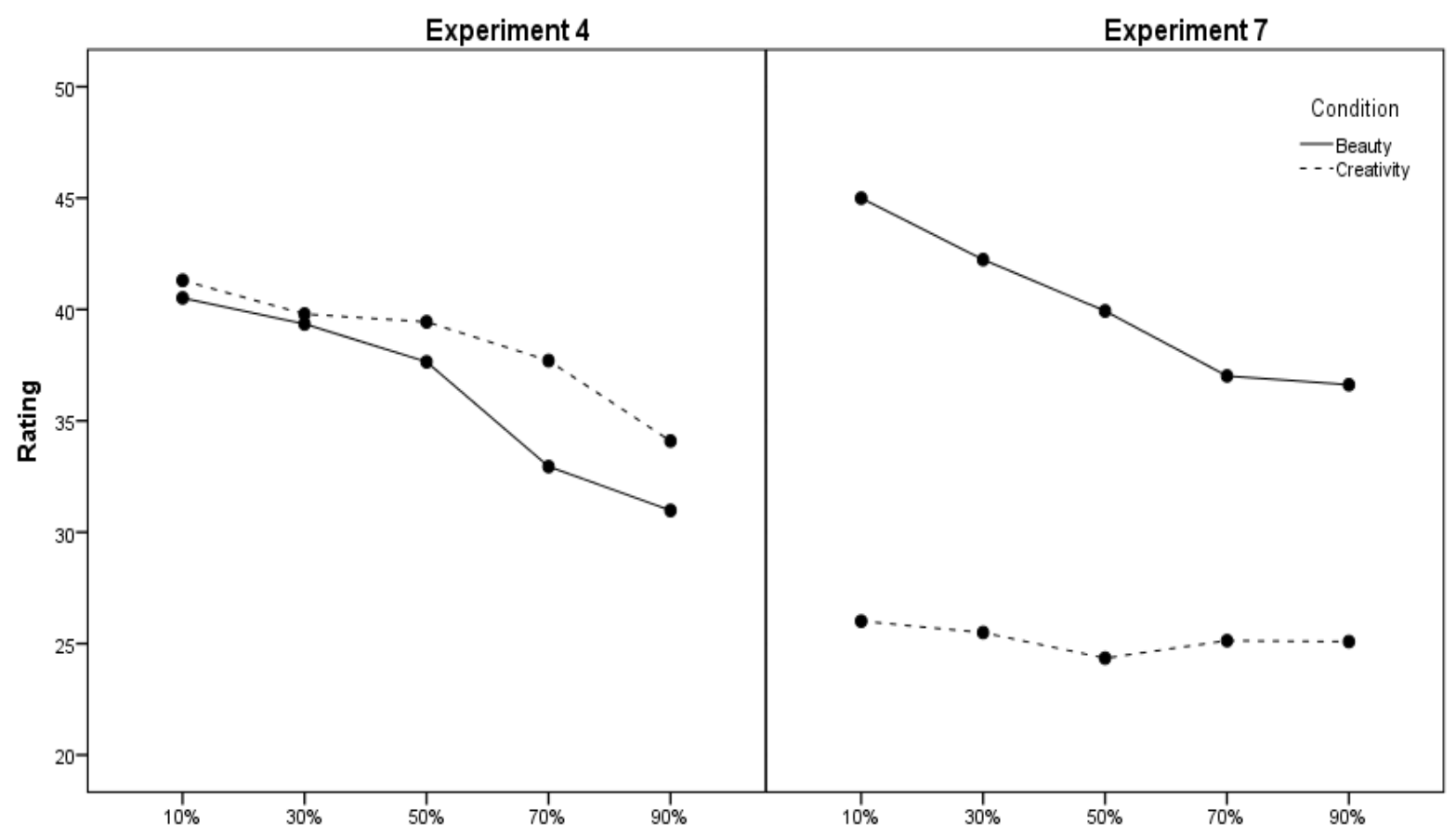

Figure-ground contrast (fluent to disfluent)

Figure-ground contrast (fluent to disfluent)

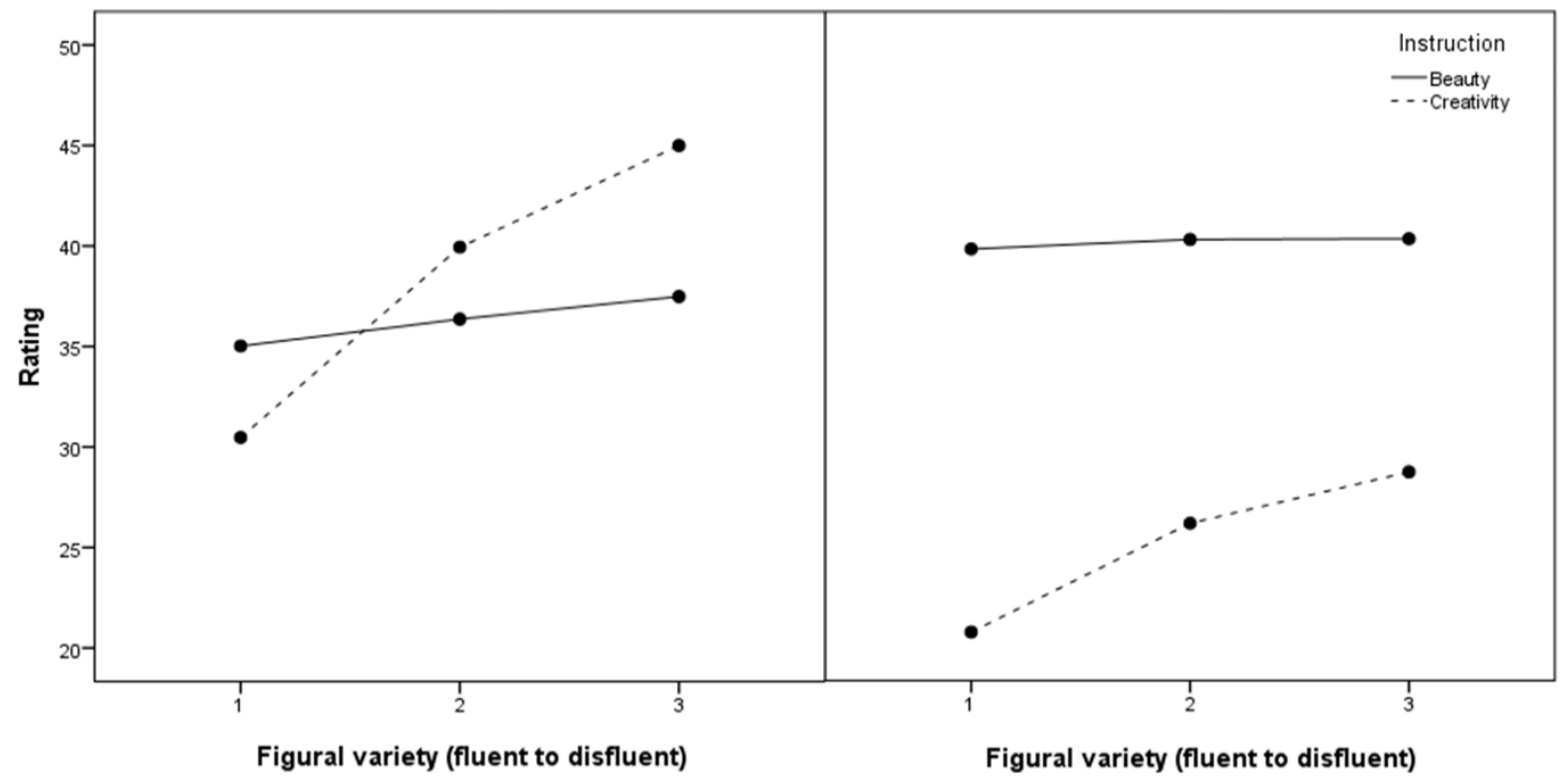

Figure 4. Ratings for creativity and beauty as a function of figure-ground contrast (top) and figural variety (bottom) in Experiment 4 (left panels) and Experiment 7 (right panels). 


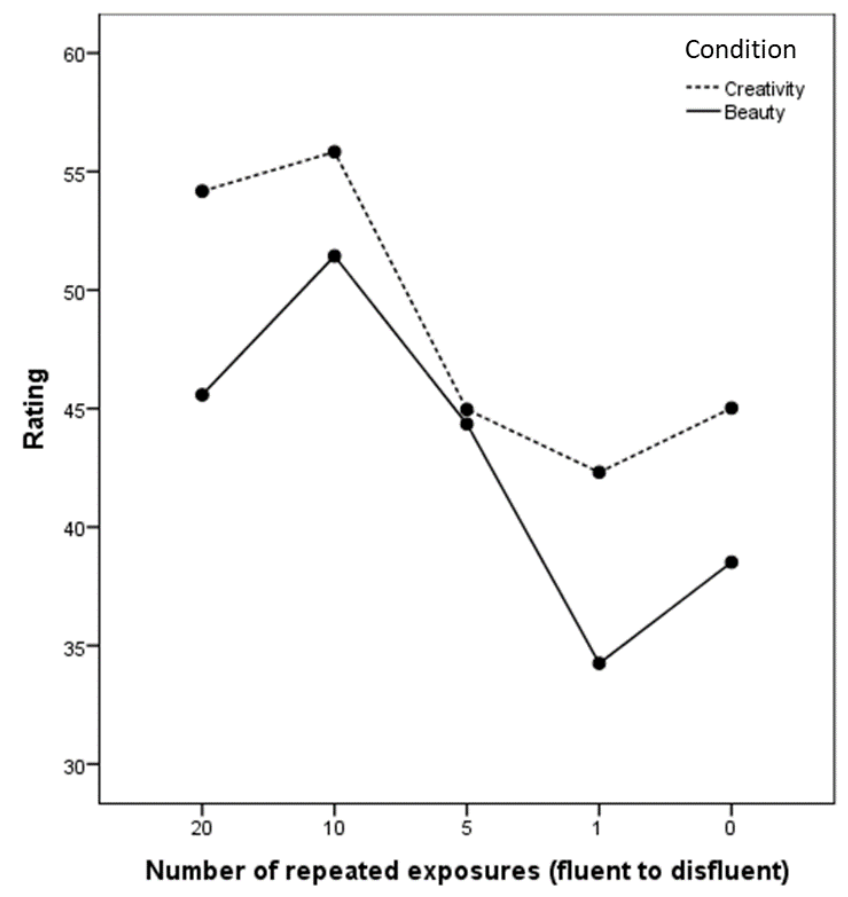

Figure 5. Ratings for creativity and beauty as a function of number of repeated exposures in Experiment 5. Note the decreasing levels of exposure along the $\mathrm{X}$-axis in order to align the presentation with that of other figures in this paper, where the $\mathrm{X}$-axis uniformly ranges from fluent to disfluent 


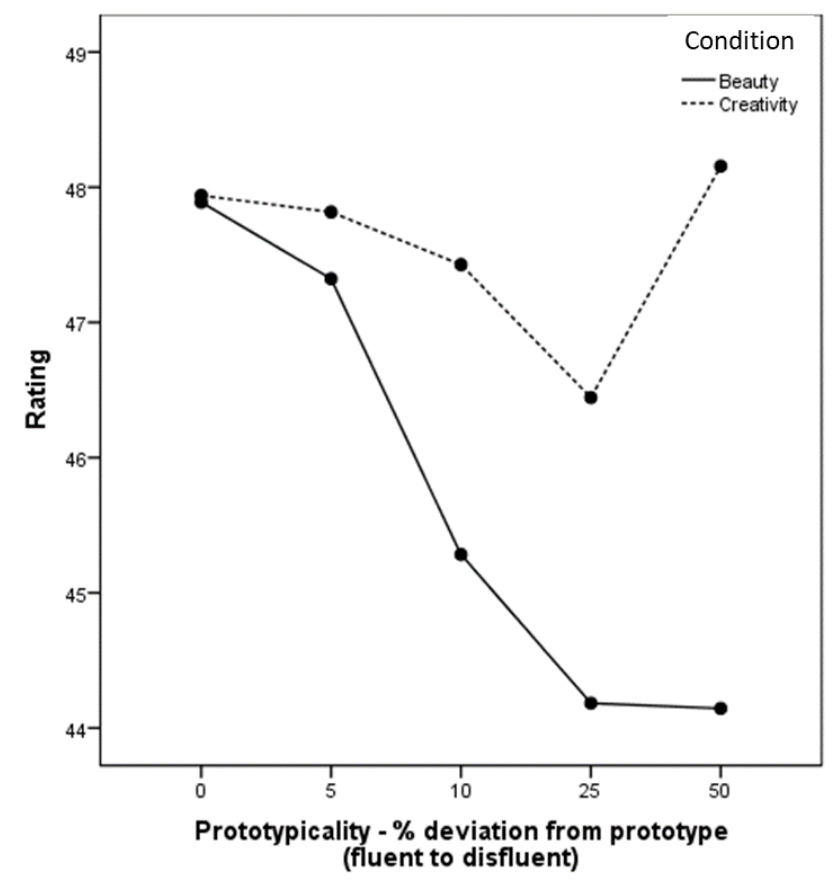

Figure 6. Ratings for creativity and beauty as a function of prototypicality in Experiment 6. 